\title{
Recreation in the Brazilian Amazon - Understanding Visitor Profile and Perceptions of Crowding
}

Lidiane Castro Gregory

Follow this and additional works at: https://researchrepository.wvu.edu/etd

\section{Recommended Citation}

Castro Gregory, Lidiane, "Recreation in the Brazilian Amazon - Understanding Visitor Profile and Perceptions of Crowding" (2017). Graduate Theses, Dissertations, and Problem Reports. 5324. https://researchrepository.wvu.edu/etd/5324

This Thesis is protected by copyright and/or related rights. It has been brought to you by the The Research Repository @ WVU with permission from the rights-holder(s). You are free to use this Thesis in any way that is permitted by the copyright and related rights legislation that applies to your use. For other uses you must obtain permission from the rights-holder(s) directly, unless additional rights are indicated by a Creative Commons license in the record and/ or on the work itself. This Thesis has been accepted for inclusion in WVU Graduate Theses, Dissertations, and Problem Reports collection by an authorized administrator of The Research Repository @ WVU. For more information, please contact researchrepository@mail.wvu.edu. 


\author{
Recreation in the Brazilian Amazon \\ Understanding Visitor Profile and Perceptions of Crowding
}

Lidiane Castro Gregory

Thesis submitted to the Davis College of Agriculture, Forestry and Consumer Sciences at West Virginia University in partial fulfillment of the requirements for the degree of

Master of Science in Recreation, Parks, and Tourism Resources

Robert C. Burns, Ph.D., Chair

David Smaldone, Ph.D. Jasmine Cardozo Moreira, Ph.D.

Division of Forestry and Natural Resources

Morgantown, West Virginia 2017

Keywords: Outdoor Recreation, Visitor Profile, Crowding, Amazon Brazil.

Copyright 2017 Lidiane Castro Gregory 


\begin{abstract}
Recreation in the Brazilian Amazon

Understanding Visitor Profile and Perceptions of Crowding
\end{abstract}

\title{
Lidiane Castro Gregory
}

The purpose of this thesis was to define the visitor profile of the Brazilian Amazon Basin using data from two different locations: The Tapajós National Forest and Anavilhanas National Park. This study also investigated possible issues regarding crowding. Overall data as well as segmented data were used in the analysis.

The methodology consisted of on-site interviews with survey days spread across weekdays and weekends. A total of 2534 usable surveys were collected from October 2015 to May 2015. All the analysis was conducted on SPSS. Frequencies, valid percentages, and means were used to describe the sample. For comparative analyzes between the two areas independent samples tests and Pearson's Chi-square tests were conducted. For the crowding analysis simple and multiple linear regressions were applied in order to understand the relationship between crowding and other variables.

The findings of this thesis revealed that there were no differences in the number of international visitors in both areas. The percentage of females recreating in the two locations was slightly higher than males. The average age of the visitors was similar although, Tapajós visitors tended to be slightly younger. Anavilhanas visitors held a lower level of education compared to Tapajós. However, in both locations overall education level was found high. Anavilhanas visitors tend to spend more time planning their visit to the area than Tapajós'. In both sites the majority were first time visitors. Tapajós visitors were more likely to visit the forest for a day trip contrary to Anavilhanas visitors who stayed in the park for more time in terms of days. However, compared to the Tapajós, Anavilhanas' day visitors spent less hours recreating in the park. For most of the interviewees, the primary reason for visiting the Amazon were to enjoy nature and experience culture. This result was similar in the two areas. Overall satisfaction was high in the sample. When compared, Tapajós visitors were more likely to report higher level of satisfaction with their experience. Crowding was not found to be an issue in this research and therefore the concept of functional density was explored. Both Tapajós and Anavilhanas visitors reported positive impact of seeing others.

This thesis hopes to contribute to the development and organization of tourism in protected areas through providing reliable data to back up management decisions. 


\section{ACKNOWLEDGMENTS}

First, I would like to thank my adviser Dr. Robert Burns, from the Amazon rainforest to the mountains West Virginia it has been a great four years of collaborative work and learning experience. Also, thanks to my committee members, Dr. Dave Smaldone and Dr. Jasmine Moreira for challenging me to always give my best.

Secondly, I am very grateful to USAID, the US Forest Service and ICMBio for funding and supporting this study in so many ways. I'm grateful for my wonderful field team in the Amazon who were vital to the role of collecting the data used in this thesis.

My appreciation to my friends and office mates who added fun to my life in Morgantown; Teri Chuprinko, Ashley Popham, Katharina Will, Jonas Levêque, Silvia Kainzinger, Emma Laferre and Micah Gregory. In special Micah for the extra support at home, from cooking meals to revising my work late at night, all my gratitude to you.

Muito obrigada a todos! 


\section{TABLE OF CONTENTS}

ACKNOWLEDGMENTS

TABLE OF CONTENTS IV

LIST OF TABLES Vi

LIST OF FIGURES vii

Statement of the Research Problem 5

Research Questions $\quad 5$

Definition of terms $\quad 6$

$\begin{array}{ll}\text { CHAPTER } 2 & 7\end{array}$

$\begin{array}{ll}\text { LITERATURE REVIEW } & 7\end{array}$

Overview Protected areas in Brazil $\quad 7$

Theories \& Fundaments 15

Perceived crowding, Social carrying capacity, and Functional density. 15

$\begin{array}{ll}\text { Cultural influence on crowding } & 19\end{array}$

$\begin{array}{ll}\text { Satisfaction } & 22\end{array}$

$\begin{array}{ll}\text { CHAPTER } 3 & 24\end{array}$

METHODOLOGY 24

Description of the Study Areas 24

Survey Instrument 29

Data Collection $\quad 31$

Testing of the Research Questions $\quad 32$

CHAPTER $4 \quad 34$

RESULTS

RQ1: What is the visitor profile of people visiting the Tapajós National Forest and Anavilhanas National Park - Amazon Brazil? 34

RQ1.1: Are there differences between Tapajós and Anavilhanas visitors? 42

RQ2: Is there a relationship between crowding and visitors' satisfaction in the overall sample?

$\begin{array}{ll}\text { CHAPTER } 5 & 50\end{array}$

DISCUSSION AND CONCLUSIONS 
RQ1: What is the visitor profile of people visiting the Tapajós National Forest and Anavilhanas National Park - Amazon Brazil?

RQ1.1: Are there differences between Tapajós and Anavilhanas visitors?

RQ2: Is there a relationship between crowding and visitors' satisfaction in the overall sample?

RQ2.1: Do age, gender, and frequency of visit affect perceived crowding on overall sample?

Recommendations for Future Research $\quad 63$

$\begin{array}{ll}\text { Conclusions } & 64\end{array}$

REFERENCES

$\begin{array}{ll}\text { APPENDIX A } & 74\end{array}$

$\begin{array}{ll}\text { SURVEY INSTRUMENT } & 74\end{array}$ 


\section{LIST OF TABLES}

Table 1: Surveys per Study Area

Table 2: Variables \& Statistics

Table 3: Sociodemographic Profile of Respondents 35

Table 4: Sociodemographic Profile of Respondents 36

Table 5: Group characteristics of Respondents 36

Table 6: Trip characteristics of Respondents 37

Table 7: Trip characteristics of Respondents Continued. 38

Table 8: Trip characteristics of Respondents Continued 38

Table 9: Trip Characteristics of Respondents Continued 39

Table 10: Reason for visit of Respondents 39

Table 11: Satisfaction of Respondents 40

Table 12: Satisfaction of Respondents Continued 41

Table 13: Respondents Perceptions of Crowding 41

Table 14: Results of Comparison of Sociodemographic 42

Table 15: Results of Comparison of Sociodemographic Continued 43

Table 16: Results of Comparison of Group Characteristics 44

Table 17: Results of Comparison of Trip Characteristics 45

Table 18: Results of Comparison of Reason for Visit 46

Table 19: Results of Comparison of Satisfaction 47

Table 20: Results of Comparison of Satisfaction Continued 48

Table 21: Results of Comparison of Perceptions of Crowding 48

Table 22: Results of Comparison of Crowding 49 


\section{LIST OF FIGURES}

Figure 1: Brazilian Protected Areas Timeline $\quad 9$

Figure 2: SNUC Categories $\quad 10$

Figure 3: Tijuca National Park 11

Figure 4: Iguaçu National Park 12

Figure 5: Carajás National Forest

Figure 6: Tapajós National Forest

Figure 7: Anavilhanas National Park. $\quad 27$ 


\section{CHAPTER 1}

\section{INTRODUCTION}

Tourism and recreation in protected areas have been increasing worldwide (Eagles \& McCool, 2002). There are a number of reasons that have led people to find alternative options of leisure and entertainment in nature. A recent study in Austria compiled literature and findings related to the benefits of woodlands/nature on human health and well-being (Cervinka et al, 2014). According to these studies, contact with nature positively affects an individual's health by providing relief from stress and attention fatigue, encouraging exercise, and facilitating social contacts. Stimulating optimal development in children, personal development, and a sense of purpose were also pointed out as benefits from contact with nature (Health Council of the Netherlands, 2004). Natural areas or woodlands have always provided a place for physical activity, but lately these areas have been included as the main component in human restoration through specific activities in the nature-based therapy segment. Cervinka (2014) argues that nature cannot be always described as a wild, untouched natural areas, it is also comprised of natural environments such as forests, cultural landscapes and, urban green spaces. Under the assumption that nature is cultivated by humans in many areas, federally-designated protected areas commonly comprise the scenery for a wide range of activities in nature. A recent article in National Geographic addressed the choice of protected areas as a site for recreational activities, demonstrating the relevance of this theme and the overall public interest in it (Williams, 2016). It is important to highlight, though, that this is not a new phenomenon. In the United States, after World War II, citizens shifted their recreational activities from urban settings to natural areas (Kraus, 2001). However, the history of recreation in protected areas is much older than 1945, 
with parks such as Yellowstone National Park making US parks some of the oldest national parks in the world. As such, the US is now recognized for having one of the most wellstructured park systems, and is an example for many countries. The field of recreation research in the US offers extensive literature and is a reliable source of material.

Moyle \& Croy (2007) drew attention to the enormous expansion in the numbers and types of users visiting natural areas around the world, not just in the US. The present study examines the case of Brazil as one of the countries facing rapid changes with a growing level of public use occurring in protected areas. Brazil is a forested country (54.4\% of its territory) and represents the second largest forest in the world (Floresta do Brasil, 2013). The Amazon region alone accounts for nearly half of the federal lands in Brazil. As of December 2010, there were 310 conservation units ${ }^{1}$ (at the federal and state level) just within the Amazon Region (Imazon, 2013). Recently conservation units in Brazil have served not only to conserve nature, but also to address the increasing demand of visitors. Data released from the Chico Mendes Institute (ICMBio, 2016) reveals a $238 \%$ increase in visitation since 2006; the total number of visitors rose from 2.99 million to 7.14 million in 2015. Considering the long history that the United States has with public use in protected areas, researchers and professionals in the US are in a unique position to assist Brazil to cope with this issue.

The Amazon region of Brazil, similar to other conservation units, attracts a variety of visitors, with increasing potential for economic development through touristic activities. According to Rodrigues de Jesus (2010), a study conducted by the Economic Research Institute

\footnotetext{
${ }^{1}$ The national term used in Brazil for protected areas is Conservation Units (UC). In this work, both terms will appear concomitantly.
} 
Foundation (FIPE) estimates that in 2006 the Amazon Region received approximately 400,000 visitors, and that the average flow of tourists to the region is about 2 million visitors per year. Although the numbers show the broad relevance of the Amazon Region, further studies related to tourism and recreation focused on protected areas are needed. Burns \& Moreira (2013) pointed out that the concept of public use management in the Amazon region of Brazil is relatively new to forest managers. In 2014 the USFS - International Programs and the Chico Mendes Institute for biodiversity and conservation (ICMBio) the Brazilian agency responsible for protected areas - initiated a partnership for the development of tourism in conservation units in this region. To fill the gap on information regarding the type of use and visitor, a systematic visitor monitoring approach was piloted in two different areas in the Amazon. The present study is based on these findings and the results are intended to be incorporated at the management level when developing regulations and policies. Therefore, the relevancy of this work consists of having active participation of the federal agency's managers and staff in the processes of implementing this new approach for monitoring visitor use in the Amazon.

Visitor monitoring studies have been crucial for the planning and organization of visitation in protected areas (Marion \& Farrel, 2002). The purpose of this study is to define the profile of recreation users from two different locations in the Brazilian Amazon Basin: The Tapajós National Forest and Anavilhanas National Park. The Tapajós National Forest is located in the eastern part off the state of Pará, approximately 852 miles $/ 1,372 \mathrm{~km}$ from the state capital of Bélem. The city of Santarém is already established as a tourist destination and serves as a main access to the Tapajós National Forest (TNF). Each year, Santarém receives around 30 international cruise ships bringing hundreds of visitors to the region. The TNF is the main attraction for those interested in learning about the rainforest. The region also attracts local 
visitors with its white sandy beaches and tropical weather. The Anavilhanas National Park (ANP) is located in Novo Airão, 119 miles/193 km from Manaus, the capital of the state of Amazonas. Manaus is considered the gateway city for the Amazon. The city has the second busiest airport of the Northern region where numerous national and international flights arrive every day. Manaus is highly urbanized and offers a wide range of attractions. For those who want to enjoy nature, the surrounding areas of the city include rural towns with pristine landscapes in the Amazon rainforest. The town of Novo Airão hosts over 400 hundred fluvial islands within the limits of the ANP; and is among the most popular destinations in the area. People visit the park for the dark waters of the Rio Negro, the interaction with wildlife, the mysterious visual of the rainforest, and the beaches in the dry season.

In both areas, recreational activities centered on vacation tourism and ecotourism have been growing, with potential not only for increasing economic capital but also for promoting preservation. Burns and Moreira (2017) emphasize the relevance of understanding who is visiting the protected areas in the Amazon and their perceptions of the visit. They also state that this understanding will set the basis for providing the best possible outdoor recreation opportunities while minimizing negative environmental impacts. The number of visitor monitoring studies in Brazil and especially in the Amazon region, as aforementioned, is still limited. To bridge this literature gap, the present study aims to analyze data from recreational users in two protected areas in the Amazon to understand demographics, trip and group characteristics, and reason for visit among the population. Also, since the concept of crowding in protected areas in Brazil is not well developed, this study also discusses how the findings relate to US-based studies. 


\section{Statement of the Research Problem}

The purpose of this study was to provide managers of Forest/ National Parks and other stakeholders with valuable information to aid the development of tourism in the Amazon Region. This includes using the findings of this study as an additional source of information in the decision-making process for conservation and public use policies.

It was also within the scope of this work to investigate visitors' level of overall satisfaction. The second aim of this study is to assess visitors' perception regarding the number of other people recreating in the two study areas. As basis for these analyses are the concepts of crowding and social density to be further explored later in this study.

In addition, this thesis contributes to the expanding United States and Brazilian literature in outdoor recreation.

\section{Research Questions}

RQ1: What is the visitor profile of people visiting the Tapajós National Forest and Anavilhanas National Park - Amazon Brazil?

1.1 Sociodemographic

1.2 Group characteristics

1.3 Trip characteristics

1.4 Reason for visit

1.5 Satisfaction

1.6 Crowding

RQ1.1: Are there differences between Tapajós and Anavilhanas visitors?

RQ2: Is there a relationship between crowding and visitors' satisfaction in the overall sample?

RQ2.1: Do age, gender, and frequency of visit affect perceived crowding on overall sample? 
Definition of terms

Conservation Units

National Forest

National Park

Perceived crowding
Brazilian natural areas under special management system with conservation goals. (SNUC, 2000)

Area predominantly covered with native species. Has as its main goal multiple sustainable use of forest resources and scientific research with focus on sustainable exploitation of native forests. (SNUC, 2000)

Area designated for preservation of natural ecosystems of great ecological relevance and scenic beauty and allows scientific research, environmental education and interpretation, recreation in contact with nature and ecological tourism. (SNUC, 2000)

Social Carrying Capacity providing a sustained quality of recreation" (Wagar, 1964)

"the subjective evaluation of density levels in a specific surrounding (Shelby \& Heberlein, 1984) and is usually defined as a negative assessment of visitor density within a given area" (As cited in Zehrer \& Raich, 2016)

Positive outcome of density and happens when the amount of perceived density is evaluated as being functional (Whiting \& Nakos, 2008). 


\section{CHAPTER 2}

\section{LITERATURE REVIEW}

Tourism and recreation in protected areas is just one among many study areas in the outdoor recreation field. Studies in this field constantly interact with other disciplines such as marketing, ecology, anthropology, etc. For instance, the impact of public visitation on the environment has been a study theme in recreation ecology (Monz et al, 2009). Another example is the economic contribution of this activity which has been studied by various researchers (Saayman \& Saayman, 2006). The marketing of these locations as a destination is also an example of cross-disciplinary research (Prideaux \& Cooper, 2003). The use of social data in all these cases is crucial. In the present study, social data were collected in order to understand the use of two protected areas by visitors. Additionally, this study assessed visitor perceptions of their experience recreating in these areas. This chapter explores fundamental concepts that will lead to a comprehensive view of the applicability of social data within the field of recreation. Other theories related to the scope of this work are also presented.

\section{Overview Protected areas in Brazil}

The history of protected areas in Brazil initiated during Brazil's colonial period (15301889) (Medeiros, 2006). However, the first National Park in Brazil was created only in 1937 the Itatiaia National Park. The Itatiaia National Park was created under Brazil's first regulation on parks and forests, the 1934 Forest Code (Drummond, 2016). Over the course of several years, Brazil's protected areas system was loose in structure and lacked technical and scientific criteria (Pádua, 1978). According to Drummond, "In the mid-1970s Brazil had created only eighteen parks - small, underfunded, understaffed, unevenly distributed among regions and biomes, plotted mostly in settled areas, and scantily visited" (2016, p.220). The 1979 Plan represented a 
milestone for recreation in the history of Brazilian protected areas. This plan was a result of a five-year collaborative effort of two organizations, the IBDF (a government agency) and FBCN - Brazilian Foundation for Nature Conservation - (an NGO) after extensive research on Brazil's resources and knowledge acquisition of global park policies. The 1979 Plan enabled proposals for the creation of other types of protected areas other than National Forests and National Parks based on technical and scientific criteria. Over time, a total of twelve categories were examined and implemented.

The combination of events in the years after the 1979 plan provided the basis for the federal legislation of the entire system of protected areas. The SNUC (National System of Conservation Units) legislation from 2000 establishes criteria and standards for the creation, implementation, and management of Conservations Units. (SNUC, 2000). The National System of Conservations Units is anchored to the following fragment of Brazil's Constitution: "It is the right for all to have an ecologically balanced environment, for a healthy quality of life and common public use, which binds the public power and the community to the duty to defend it and preserve it for present and future generations" (Brasil, 2013a, p.36 translated). This legislation requires the State to defend the rights of all Brazilian citizens by allowing the creation of areas with the goal of conserving biodiversity (Garcia, 2015).

It is pertinent to mention that since the creation of the first National Park, various institutions have overseen protected areas in Brazil. The timeline below shows all these institutions: 


\begin{tabular}{llllll}
1937 & 1938 & 1967 & 1973 & 1989 & 2007 \\
\hline Creation of & Brazilian & Brazilian & Special & Brazilian & Chico Mendes \\
Brazil's first & Forest & Institute of & Secretary of & Institute of the & Institute for \\
National & Service & Forestry & Environment \\
Park & & $\begin{array}{l}\text { Development } \\
\text { (IBDF) }\end{array}$ & (SEMA) & $\begin{array}{l}\text { Environment } \\
\text { and Renewable }\end{array}$ & $\begin{array}{l}\text { Biodiversity } \\
\text { and }\end{array}$ \\
& & & $\begin{array}{l}\text { Natural } \\
\text { Resource }\end{array}$ & $\begin{array}{l}\text { Conservation } \\
\text { (ICMBio) }\end{array}$ \\
& & & (IBAMA) &
\end{tabular}

Figure 1: Brazilian Protected Areas Timeline

*Souza, 2016.

To reinforce and support the development work, the Brazilian Federal Agency Chico Mendes Institute for Biodiversity and Conservation (ICMBio) was created in 2007. ICMBio, overseen by the Ministry of Environment, is responsible for the management of federal conservation units. For several years after the creation of Brazil's first national park, protected areas were under administration by several separate institutions. The absence of a reference institution certainly impacted the development of these areas in terms of policies, management, allocation of resources, and primarily, visitation (Souza, 2016).

According to Medeiros \& Young (2011) after the formation of the National System of Conservation Units (SNUC) the number of protected areas in Brazil doubled. The SNUC is a set of standards for the creation and management of federal, state, and municipal conservation units. The Brazilian National System of Conservation Units (SNUC) first divides protected areas in two groups with distinct characteristics; integral protection conservation units and sustainable use conservations units. Within these two types are twelve use categories. See the graphic representation of the SNUC below: 


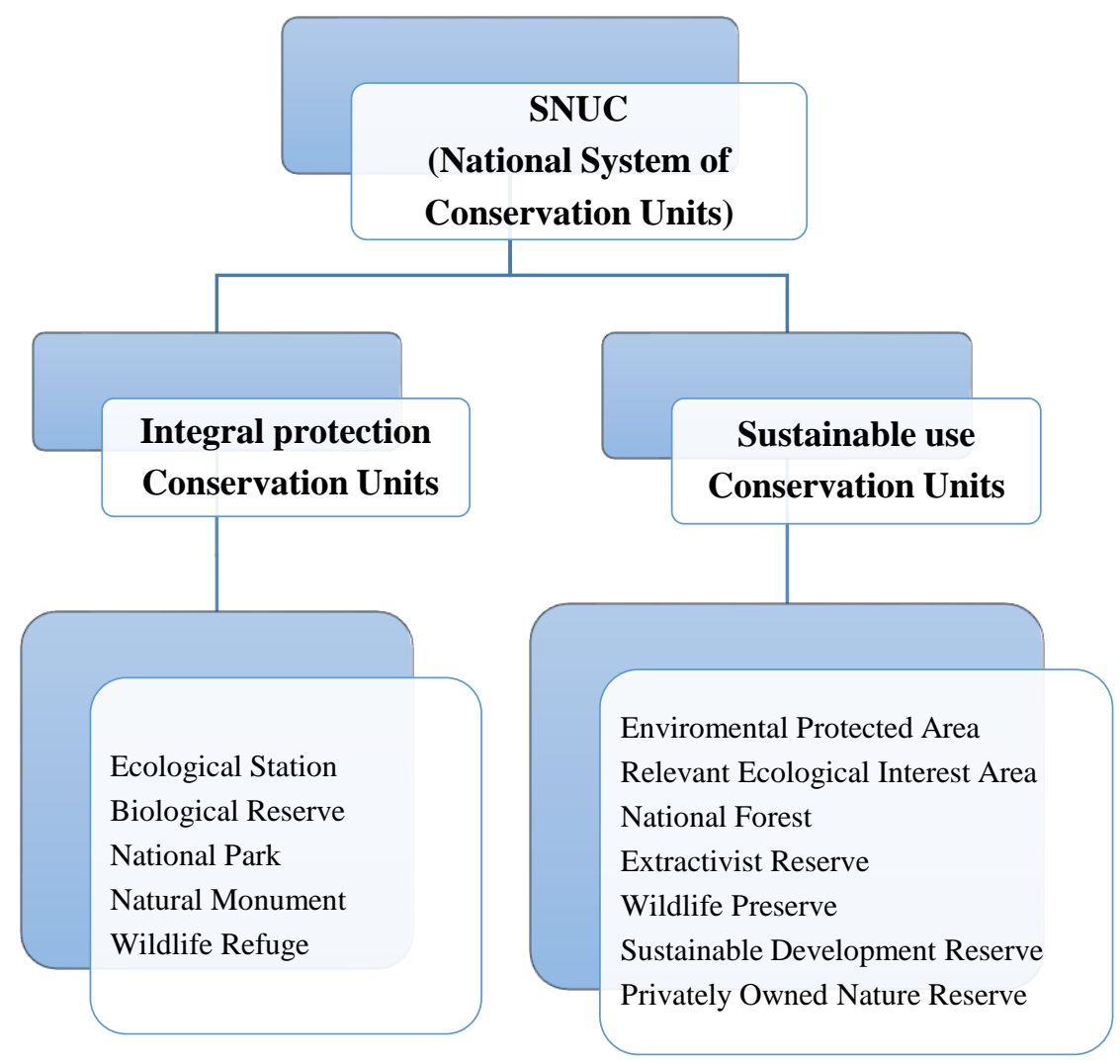

Figure 2: SNUC Categories

This thesis focuses on two of these categories, National Park and National Forests.

National Parks fall under the integral protection group, which aims to preserve natural ecosystems of great ecological relevance and scenic beauty. This category emphasizes scientific research, environmental education and interpretation, recreation in contact with nature and ecological tourism (SNUC, 2000 translated). In its essence, National Parks are and should always be open to public visitation. However, budgetary problems and lack of management and visitation plans have made some parks in Brazil remain inaccessible to visitors. National Forests are considered a sustainable use conservation unit that focuses on the sustainable use of forestry resources and scientific research (SNUC, 2000 translated). In this category, public use visitation is permitted, conditioned upon the regulations established on the management plan of the 
conservation units. Also, the sustainable use of the forest should benefit the traditional population residents of the area. According to Souza (2016), visitation data from 2015 reveals that the most visited conservation units are the National Parks and National Forests categories (90\%). The two most visited Brazilian conservation units are located in the Southeast and Southern regions of Brazil, Tijuca and Iguaçu National Parks. There is only one National Forest listed in this ranking, the Carajás National Forest situated in the Amazon region - north of Brazil. In 2015 the Tijuca National Park received a total of 2,945,355 visitors (ICMBio, 2015).

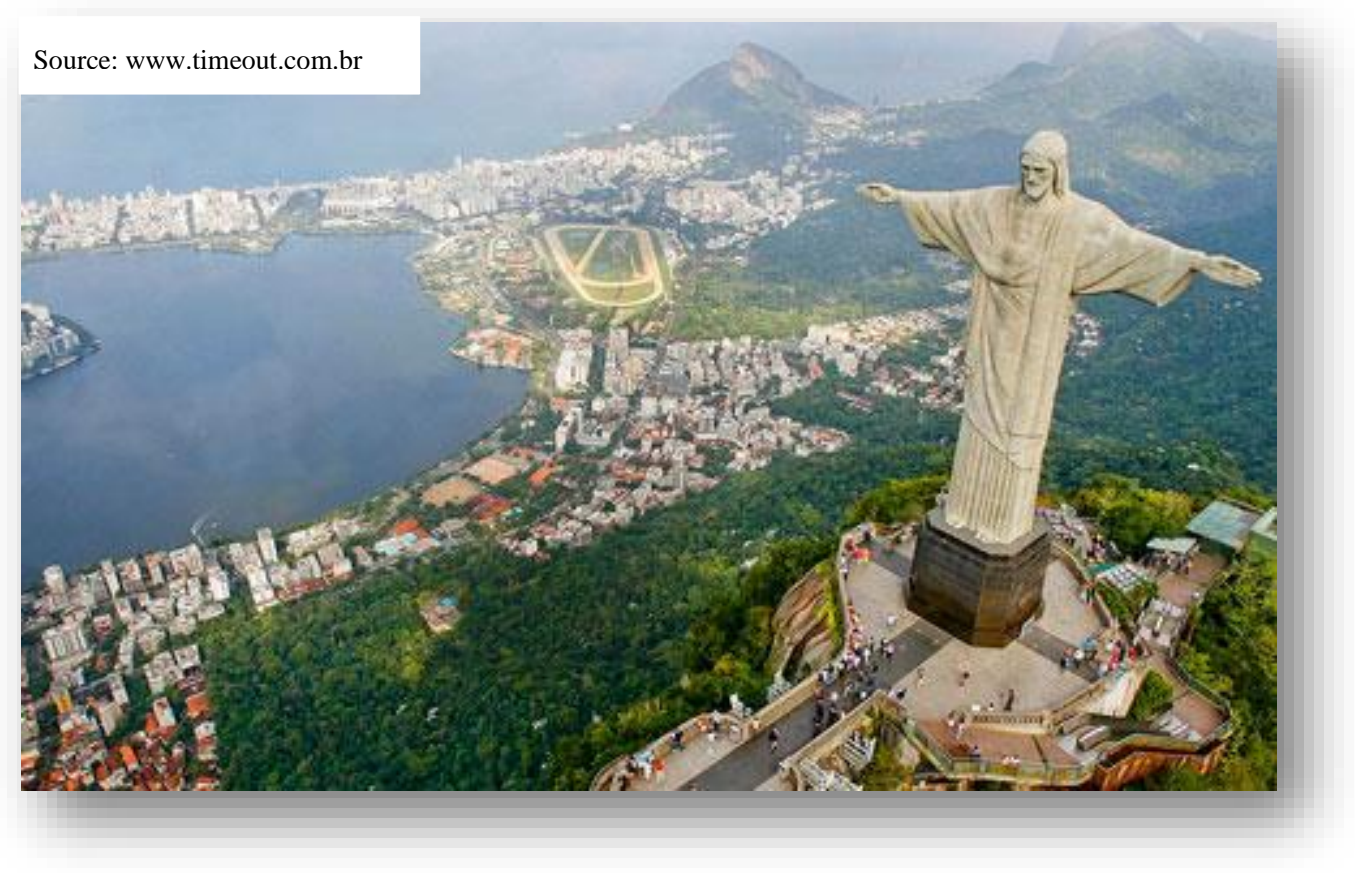

Figure 3: Tijuca National Park 
The Iguaçu National Park received a total of 1,642,093 in 2015 (ICMBio, 2015).

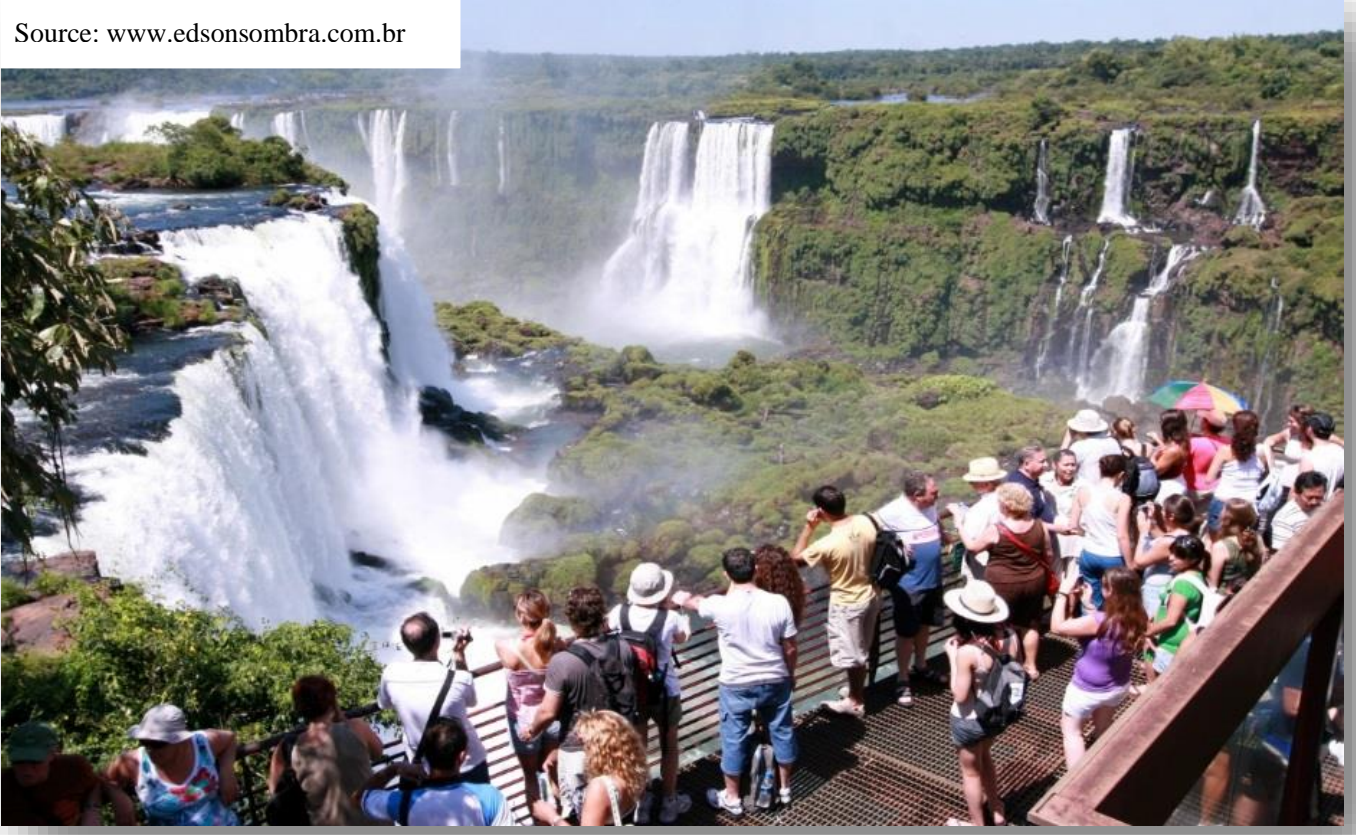

Figure 4: Iguaçu National Park 
In 2015 the Carajás National Forest had 194,450 visitors (ICMBio, 2015).

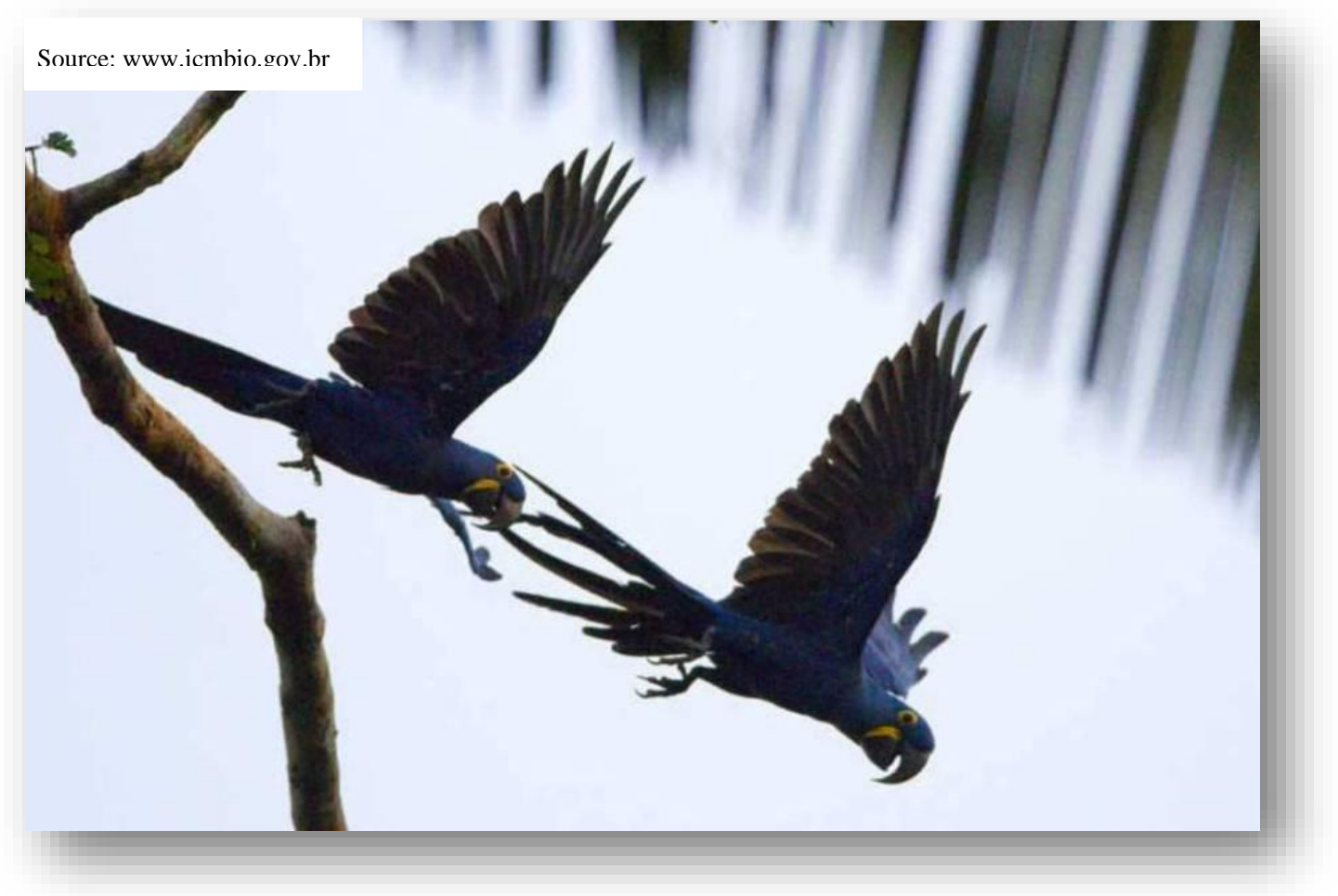

Figure 5: Carajás National Forest

At the federal level, Brazil has 73 national parks, 67 national forests, and a total of 325 conservation units distributed within other categories (MMA, 2016). The majority of the conservation units are located in the Amazon rainforest with a total of 141. Visitation in protected areas of the Amazon is still considered low compared to other regions of Brazil. Nevertheless, the potential for growth, primarily from an ecotourism perspective, stands out as an opportunity. Viveiros de Castro et al. (2015), when analyzing the difference in visitation among the National Parks in Brazil, attributed the low visitation to the lack of opportunities and infrastructural development. These authors also emphasize that budgetary constraints and absence of societal support might contribute to this current situation. In a recent study, Burns \& 
Moreira (2013) compared Brazilian protected areas with those in the United States and Central Europe. Their findings reveal that the creation and management of protected areas in Brazil is based on an eco-centric view, with little attention was given to the role of recreation in these areas. This also might explain why Brazil's protected areas, although well suited for recreation, still receive significantly fewer visitors when compared to visitation of protected areas within the US. It is worth mentioning that this disparate distribution in visitation within protected areas in Brazil can lead to negative consequences. Environmental impacts and congestion caused by the number of people visiting that same area are some examples of negative impacts. Management implications regarding infrastructure, environmental monitoring, and visitor monitoring should also be taken into account. Recently, Brazil has been going through a slow transition toward viewing its protected areas in a more anthropocentric manner and leaving room for visitor use (Burns \& Moreira, 2013).

In terms of managing conservation units, Brazil was specifically influenced by the US through the diffusion of two movements, preservationist and conservationist. These two terms are often treated as synonymous due to their relation to protection. However, their differences are found in the way protection is performed or achieved. The preservationist represented by John Muir approaches protection as protection of nature from use (White, 1985). The natural resource should be subject to minimum or non-human intervention; this way, protected areas would become isolated islands from economic and social reality (Pimentel \& Magro, 2011). On the other hand, conservationism for Pinchot means protection through proper use of nature (White, 1985). The natural resources should be used in a rational manner, meaning that human use should be regulated for the use of resources by present and future generations and waste prevention. Even though the management of protected areas in Brazil presents traits of both 
concepts in its core system, the preservationist appears to be more prevalent, therefore diverging from the US. Another important aspect of the history of Brazil's protected areas that diverges from the US is related to maintaining the livelihood of native/traditional populations living in areas designated as national parks or protected areas. This was a concern noted by the International Union for Conservation of Nature (IUCN) which was later incorporated into the creation of Brazil's own protected areas' system. It is important to highlight that tourism in protected areas, if well planned, can leverage economy of small populations living in and within the limits of these areas. There is also an opportunity to promote conservation and awareness through increasing visitor's sense of stewardship.

\section{Theories \& Fundaments}

\section{Perceived crowding, Social carrying capacity, and Functional density.}

Perceived crowding has emerged as a critical area in retail and shopping research (Eroglu and Harrel, 1986; Hui and Bateson, 1991). Perceived crowding was first defined by Shelby \& Heberlin (1984) in the outdoor recreation field as the subjective evaluation of density levels in a specific surrounding. This concept has been applied to many academic fields with a primary focus on negative effects (Graefe, Vaske, \& Kuss, 1984). In outdoor recreation, perceived crowding has appeared as the trigger of recreation conflict (Kainzinger, Burns, \& Arnberger, 2015; Moyle \& Croy, 2007), and as part of studies in recreational quality and visitor's satisfaction (Wagar, 1964). Manning (2011) defined crowding as the notion that there is some level of visitor use beyond which the quality of the outdoor recreation experience is diminished to an unacceptable degree. National Parks/Forests and wilderness areas have served as main research settings for these studies and this is due primarily to the implication that crowding has ecological impacts associated with tourism in protected areas (Moyle \& Croy, 2007). According 
to Zehrer \& Raich (2016, p.89), “crowding issues arise when a large number of people is gathered together, and the usage of environmental and/or social resources exceeds the limit by physical environment." Another concept associated with perceived crowding is that of carrying capacity, which encompasses the environmental and social aspects of capacity (Manning, 2011). The term originated in the natural resources field and refers to the ultimate limit of animals or species that an area or habitat can support without causing any kind of damage to the environment. The notion of carrying capacity was extended to a social level and applied to outdoor recreation studies by Wagar; he stated: "carrying capacity is the level of recreational use an area can withstand while providing a sustained quality of recreation" (J.A. Wagar, 1964, p. 3).

With the growth of recreational activities in protected lands such as National Parks and Forests, managers became more interested in incorporating social carrying capacity in management decisions. The use of carrying capacity applies to outdoor recreation and is comprised of three dimensions: resource, social, and managerial (Manning and Lime, 1996; Manning, 2011). Manning (2011) explains how these three levels are intertwined; natural resources are affected by the number of people visiting a recreation area and this can impact ones' recreation experience as well. Embedded in this are the management activities that have direct impact on both resource and social dimensions. For example, implementing good practices of taking care of the environment (e.g. soil fertilizing, rotation of impact sites) ensures the durability of a natural resource. Just as actions such as visitation rules, even distribution of visitors, provision of facilities, and others can increase the quality of visitors' recreational experiences. Furthermore, at a managerial level, it is possible to use perceived crowding as an evaluative standard for social carrying capacity to determine the appropriate number of people in an area (Manning, 2011). The concept of crowding implies numbers and contact with people and 
allows this connection with social carrying capacity to be explored. The only limitation of using this approach is that other personal, social, and situational factors affect crowding perceptions which makes it difficult to establish a standard for determining the point at which crowding reaches unacceptable levels (Shelby \& Heberlein, 1986)

The basis of perceived crowding is rooted in the theory of psychological reactance. Reactance happens when free behavior is restricted by outside interference restricting in the ability to choose certain activities. (As cited in Moss, 2016). For instance, one individual's freedom can become restricted by invasion of personal space and this can cause reactance. This reactance can be manifested in different ways. In recreation, perceived crowding commonly results in coping behaviors such as visitor displacement, rationalization, and/or activity substitution (Marion \& Reid, 2007). A brief description of each of these conceptions is necessary in order to better establish the basis of this section. Coping is a well-known concept in psychology and can be defined as "any behavior, whether deliberate or not, that reduces stress and enables a person to deal with a situation without excessive stress" (Sutherland, 1996). Based on Manning (2001), Visitor displacement occurs when visitors alter their recreation patterns to avoid crowding; Rationalization might happen when some visitors, to reduce internal conflicts, report high levels of satisfaction regardless of the actual conditions of their experience; and last, Activity substitution or product shift takes place when visitors, due to high use levels, alter their original activity to conform with the conditions experienced. It seems to be apparent that physical density is a key component of all these issues. Density can be defined as the number of people and/or objects in a given space (Drintewater and Gudjonsson, 1989). Although the concepts of crowding and density have some similarity, they are not interchangeable (Stolks, 1972). Eroglu and Machleit (1990) state that density is an antecedent condition of crowding and 
plays a central role in the appraisal of crowding. Additionally, density is a physical condition of the environment while crowding is a response to or appraisal of the environment (Eroglu and Machleit, 1990; Stokols, 1972). In line with this are the studies of individual cognitive differences as a determinant of someone's experience with/of crowding (Schmidt \& Keating, 1979). A series of researchers (Sonnenfeld, 1966; Freedman et al., 1972) have pointed out that one's personal values, attitudes, and expectations somewhat influence judgment and need for space. Schmidt \& Keating (1979) summarized, "thus, the effects of density are determined by who is being crowded and by the situations and behaviors involved."

Understanding that crowding is relative to the individual and the situation, a high density situation may not necessarily result in the negative and stressful outcome called crowding. Instead, it may result in an outcome called functional density (Eroglu and Harrel, 1986). Literature on crowding and density has shown that different density levels affect individuals differently in terms of perceptions of crowding. According to Baum and Paulus, "in some conditions and for some people, a given level of density may lead to crowding while in other conditions or for other people it may not" (Whiting \& Nakos, 2008, p. 6 ). The study of the positive side of crowding was first introduced in the marketing discipline by Eroglu and Harrel (1986). Now many other academic fields have appropriated the concept including tourism, environmental psychology and lately the recreation field.

Few studies (e.g. Heberlein, Trent, \& Baumgartner, 1982; Heberlein \& Kuentzel, 2002) in the recreation field have focused on specific cases in which the number of people participating in a recreational experience has a positive impact on the visitor experience. Among these studies is the work of Ditton and colleagues (1983) who examined perceptions of crowding in a river recreation setting and identified a subgroup of floaters who considered participant density a 
positive attribute leading to increased enjoyment of the experience. A more recent study exploring the relationship between crowding and satisfaction identified a subgroup of deer hunters who reported reduced satisfaction with their experience due to the low density of other hunters (Gigliotti \& Chasen, 2014). In this study, the researchers propose a holistic approach to crowding that encompasses circumstances in which low density may not represent overall satisfaction.

\section{Cultural influence on crowding}

When looking at crowding, there are many variables that can serve as subjects of study such as sex and gender, race and ethnicity, age, and social groups among others. One factor that has received attention over the years is culture and its role in outdoor recreation. Rapoport (1980) conducted a relevant study in cross-cultural aspects of environmental design that is still valid and recognized as the basis for cross-cultural studies in various disciplines. Rapoport argues that "[c]ulture affects both the physical environment and the responses of people to the environment" (1980:p.118). Understanding how Brazilian culture reacts to recreation issues such as crowding can result on improvements of the management of recreational activities in Brazilian protected areas.

Studies from retail shopping have pointed out the influence of culture on perceptions of density and evaluations of crowded situations (Pons et al., 2006). According to Iwata (1992), the state of being crowded differs across cultures. Culture has been shown to produce different responses to high density situations. Also, research on culture and privacy has shown that some cultures have a stronger preference for privacy, which could alter perceptions of crowding (Whiting \& Nakos, 2008). Understanding the value of these findings, outdoor recreation researchers started investigating how the cultural component influences the way people recreate 
as well as the management of these recreation areas. Vaske and colleagues (1996) listed a series of authors and their contribution to this topic by examining culture and its relation to participation in outdoor recreation, urban park use, preferences and behaviors, landscape preferences, values and perceptions, and crowding.

Vaske et al. (1996) conducted a study in a frontcountry setting - Jasper National Park focusing on cultural norms and crowding by using the independent variable country of origin as an indicator of culture. An interesting result of this study noted that respondents from Japan, Germany, and Great Britain - countries where densities per land area are higher - were more likely to specify a norm (number of encounters acceptable). Another research study (Sayan et all, 2013) analyzed the cultural influence on crowding norms in outdoor recreation using data from a National Park in the United States and another in Turkey. This comparative study had three nationalities represented, Americans, Britons, and Turks. Similarities and differences were found, with overall results demonstrating that Turks tend to be more socially-oriented than Americans and Britons, and British visitors appeared to have more tolerance for crowds than Americans. The authors argue that this may be due to America's history related to a search for solitude in nature. This way of thinking is so embedded in America's history and culture that consequently it was incorporated into the Wilderness Act (1964).

Hall (1966) introduced the concept of cultural tolerance for crowding using proxemics and collectivist culture theories as a basis of his argument. Proxemics theory is based on the premise that residents of contact cultures (e.g. Latin, Asian, Arab) prefer closer interpersonal distances than noncontact cultures (e.g. Northern European, North American). A collectivist culture is the one that is based on valuing the needs of a group or a community over the individual (e.g. South Korea, Russia, Peru). According to Hall (1966), cultures that prefer to 
interact at larger interpersonal distances will be less tolerant of crowding. Allen (2000) questions the construction of cross-cultural differences in tolerance for crowding pointing to the absence of substantial data to substantiate the generalization. This same author conducted a study based on residential density and used samples from different cultures to analyze whether tolerance for crowding varies by culture. Although differences were found in the way collectivist cultures perceived residential density compared to Anglo-Americans, the cultural groups did not differ in their psychological distress to density. These findings were based on the understanding that crowding tolerance denotes better or improved ability to withstand the adverse effects of highdensity areas. Stokols (1972) stated that crowding has also been considered a state of psychological stress. Allen's study approached tolerance by using a nonclinical measuring instrument to assess participant's psychological level of distress. This author emphasizes the existent - but not well studied or propagated - distinction between crowding tolerance and variability in interpersonal spacing norms.

The research mentioned above does not invalidate previous contradictory outcomes, it just reinforces the need for more research including diverse situational contexts and among different cultures. "Crowding occurs in many different settings ranging from retail store to a sporting event." (Whiting \& Nakos, 2008, p.7). This last situation differs from the first one due to its hedonic nature, which give place to fun, amusing, exciting, and pleasurable experiences (Babin, Darden \& Griffin, 1994). Research using hedonic settings are scarce (Pons et al., 2006). Already putting into a recreation perspective, Manning (As cited in Zehrer \& Raich, 2016) points out that crowding can be mediated by the context of the situation and thus studied by focusing on the respective cause of perceived crowding. Overall, recreation studies related to perceived crowding and culture do not present a consensus in their findings which could be used to 
strongly state that different cultures have perceived crowding differently. Conceptual and methodological problems may complicate the development of a body of literature comparing data across nations and cultures.

\section{Satisfaction}

In recreation management, visitor satisfaction is a frequently stated goal, however, the complexity of this term has contributed to many managers failing to achieve this goal. Dorfman (1979) states that without understanding how people evaluate the quality of an experience, it is challenging to provide quality environments for various user populations. This author urges the need to better understand the psychological processes involved in recreational choice and feelings of satisfaction, as well as their measurements. Since then, literature in satisfaction has expanded and many authors have contributed with different views, strategies, and models to assess visitor's satisfaction. However, one of the most influential studies in satisfaction dates back to 1977 (Herberlein and Shelby) and defines satisfaction in recreation as an outcome of the visitor experience that is usually associated with crowding. This initiated the use of the satisfaction model in recreation studies. It assumes that, for the individual, increased use causes decreased satisfaction (Manning, 2011). However, when tested in a variety of recreation settings, this bivariate model did not show a strong relationship between the two variables. In fact, the relationship between crowding and satisfaction was found to be generally weak or nonexistent (Manning, 2009). The satisfaction model was then expanded to a more comprehensive model incorporating theoretical approaches to crowding from numerous researchers. This model consists of ten components or variables that are correlated with visitor satisfaction. Perceived crowding is only one of these components. Based on studies that have tested the expanded satisfaction model, Manning (2011) highlights that several methodological issues can affect the 
relationships among the following three components of the model and variables: use level, crowding, and satisfaction. These issues are related to how these variables are conceptualized and measured.

Satisfaction in outdoor recreation can also be explored from a different perspective. Lee, Graefe, and Burns (2004) draw attention to the relationship service quality and satisfaction. These authors were particularly interested in the criteria visitors use in evaluating quality and experiencing satisfaction. Service quality and satisfaction can be used as indicators of profitability and success in the fields of recreation, tourism, and marketing. In that sense they emphasize the notion that satisfaction is moderated by subjective factors that may not be in power of managers (e.g. weather, crowding, conflict, and social groups). However, there are others objective determinants that manages can interfere such as social problems (e.g. littering, human noise, and vandalism). Management actions can reduce the impact of these factors on visitor's satisfaction. 


\section{CHAPTER 3 \\ METHODOLOGY}

In this chapter, the methodology used in this study will be described, as well as a detailed description of the study areas. The data collection was a product of the Federal Financial Assistance Award of Domestic Grant 14-DG-11132762-156, between West Virginia University and the USDA Forest Service, International Programs. WVU provided visitor monitoring services for the National Forest/Park. The methodology applied to the data collection process was pioneering in the Amazon region and remains one of the first of its kind in all ICMBio (Chico Mendes Institute for Biodiversity) conservation units in Brazil. It is the same model used in US National Forests and Parks which was designed to provide an estimate of recreation visits and help ensure consistency in data collection establishing a minimum standard of statistical accuracy (English et al., 2002).

\section{Description of the Study Areas}

The 9.985 Act from July $18^{\text {th }}$ of 2000 established the SNUC that secures the creation of, among other categories, National Parks and National Forests. The two areas of this study illustrate the use and management of these two different categories per its purpose.

\section{Tapajós National Forest}

The Tapajós National Forest (TNF) created in 1974 was the second National Forest to be created in Northern Brazil and the second one in the Pará state. The area consists of approximately 1,356,773 acres/549.066.87 hectares and has as its boundaries the Tapajós river on the western border, and the BR163 (Cuiabá - Santarém highway), to the east. The municipality of Belterra marks its limits on the north and the municipality of Rurópolis its limits 
south. The area encompasses the municipalities of Placas, Rurópolis, Belterra, and Aveiro. As other conservation units in the Amazon, the TNF originated as a counterparty to a government occupation project that supported farming families to migrate to the Amazon. This project included construction of "colonization-highways". In the surrounding areas of these projects and highways conservation units were created as a mechanism for protection of resources (Bacha \& Rodriguez, 2004).

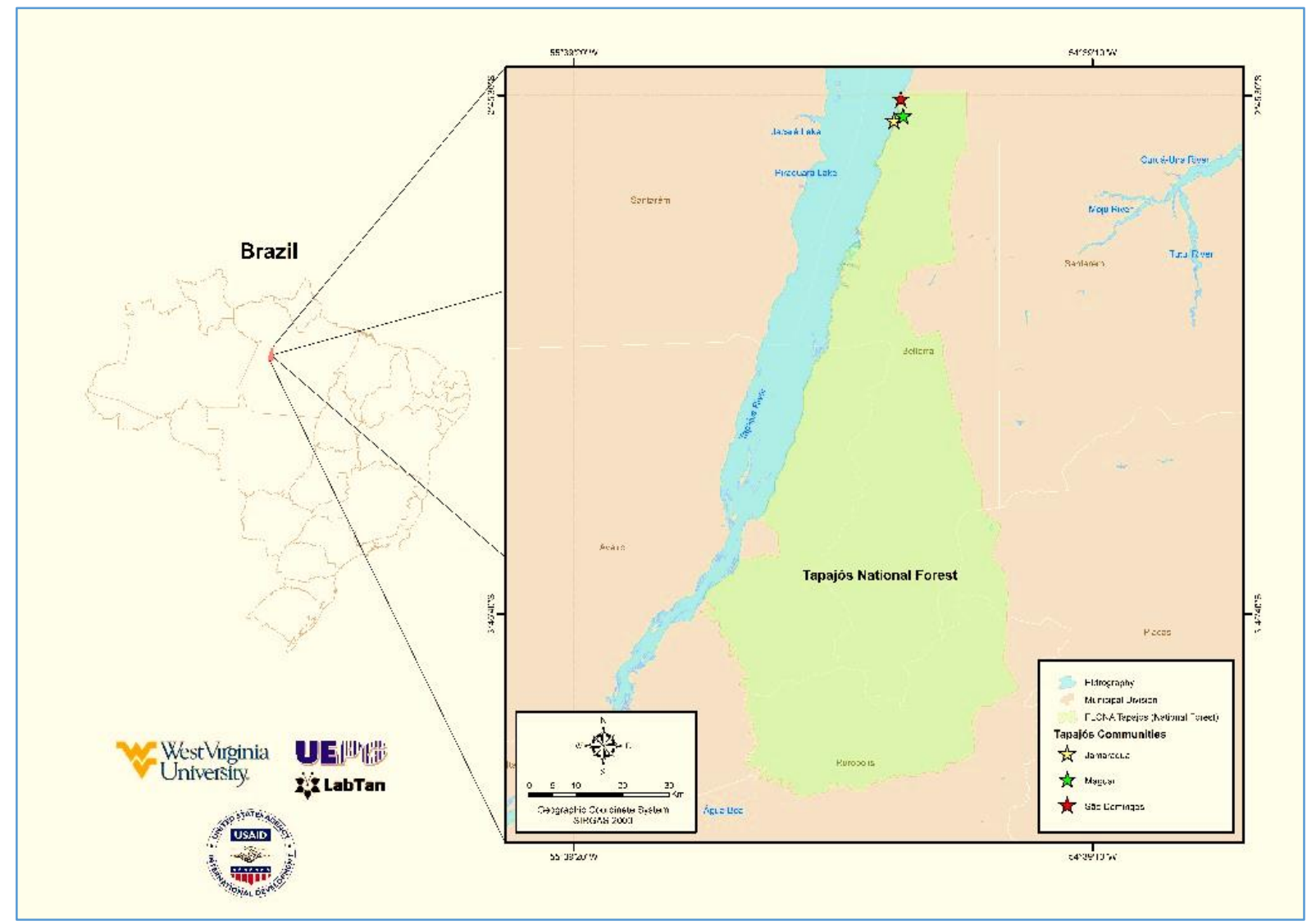

Figure 6: Tapajós National Forest

Access to the Tapajós National Forest is possible via boat or car from the city of Santarém, which is the nearest international airport and dock. Fluvial access takes 5-6 hours to one of the first three communities. The distance by land is approximately 31 miles $/ 50 \mathrm{~km}$ via BR 163. The wet season worsens road conditions and depending on the season, the trip can take 
between 1.5-2.5 hours. The Tapajós National Forest presents a varied landscape that includes 99 miles /160 km of freshwater beach, native forest, lakes, swamps, dryland woods, hills, grasslands, and native acai berry plantations. Dry seasons and wet seasons influence the landscape but recreation activities are available through the whole year. Opportunities for hiking, swimming, watching wildlife, canoeing, learning about local culture through visiting the communities, and buying sustainable products are some of the activities offered to the tourists independent of the season. Besides the physical attributes, the TNF is characterized by the diversity of its inhabitants. Over 4000 traditional dwellers are distributed in 21 communities living in the TNF. Three of those communities are considered indigenous from the Munduruku ethnicity. Accordingly, the sociocultural aspect is also an attraction for tourists interested in learning about the Amazonian lifestyle.

Tourism in the Tapajós National Forest appears to be a longstanding activity, however it was only in 1993 that regulations regarding recreation were established (e.g. permits, charging access fees). An ecotourism study authored by Tanner (1997) can be considered the first one seeking to identify the profile of potential tourists to the Tapajós National Forest. The primary aim of that work was to gather information for the development of an ecotourism plan. The findings of this study were used to justify investments in tourism in the following years. It also provided information for the public use section of the management plan of 2004. As mentioned earlier, the two pillars of National Forests are sustainable multiple use of forest resources and scientific research. Recreation activities are only permitted if noted in the management plan. Despite development efforts and investments, tourism on the TNF continues to be rustic in nature. The facilities are simply redários (hammock lounges) built as an extension of a resident' house who offer meal services. 


\section{Anavilhanas National Park}

The Anavilhanas National Park (ANP) is located in the state of Amazonas, situated119 miles $(193 \mathrm{~km})$ from Manaus, the capital. The area consists of 864,913 acres/350,018 hectares in which 28 percent of this area is in the territory of Manaus and the other 71 percent within the municipality of Novo Airão. The Park is bounded to the north and east by the Rio Negro. Novo Airão is the main point of access to the park either by land or water. From Manaus by car the AM-352 that connects Manaus - Manacapuru leads to Novo Airão - it takes a distance of approximately 2-3 hours. This same route is accessible by public transportation. Via water, depending on the type of vehicle, it can take between 3 to 9 hours traveling.

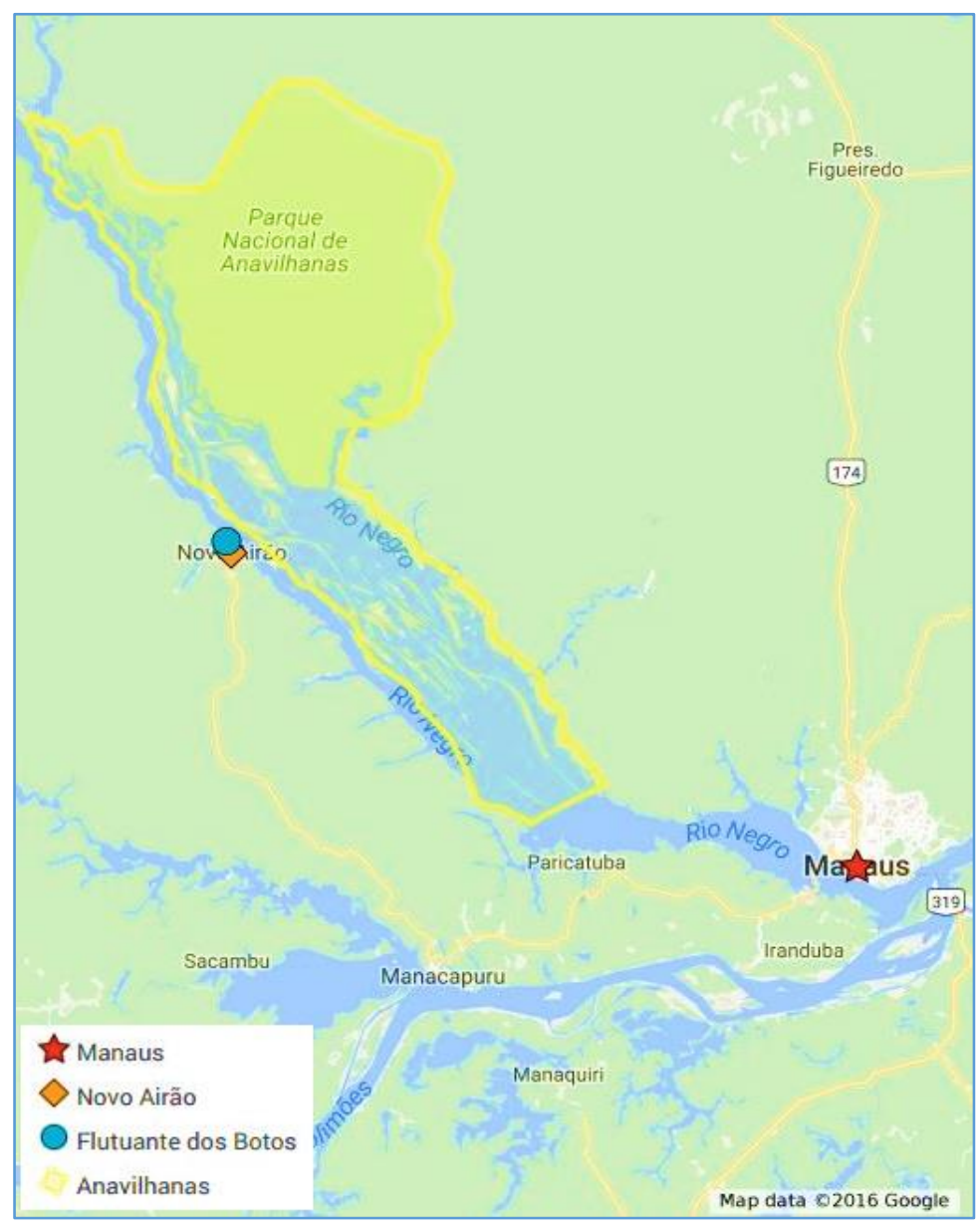

Figure 7: Anavilhanas National Park. 
The park was originally created as an Ecologic Station in 1981 with the purpose of protecting the ecosystem represented by the Anavilhanas fluvial archipelago in the Rio Negro. Public use was not allowed until 2008, when the area was re-categorized as a National Park. The management plan of this Conservation Unit is under revision to better suit its new category. One of the primary differences between a National Park and Ecological Station is their openness to public visitation. The goals of Ecological Stations are nature preservation and scientific research; public visitation is not allowed unless it is noted in the management plan or upon specific regulation (SNUC, 2000). In 2012, the ICMBio issued a temporary ordinance regulating public use activities in the park (Diário Oficial da União, 2012). This ordinance intended to minimize the eventual impacts of visitation on the natural environment.

The Anavilhanas National Park is well known for having one of the largest archipelagos in the world. The 400 islands provide a unique scenery that attracts visitors from a variety of places. The landscape of the area presents dense rainforest, dryland woods, woodlands, campinarana, igapó (backwater-flooded Amazonian forest), and beaches. Contrary to the Tapajós National Forest, there are no communities living within the Park. During the dry season, the activities available include swimming at the beaches and hiking. During the winter, visitors have the chance to go on aquatic trails through the flooded forest. In both seasons, visitors can go on tours to watch wildlife, take scenic flights, shop local products, and interact with the Amazonian dolphins or porpoises. According to Romagnoli (2009), the activity with the dolphins has been ongoing since 1998. However, it was only established as one of the park activities in 2010 and thus subject to regulations. Visitors now are given an educational briefing about the animals and rules of the visit. Only staff members are allowed to feed the animals and the number of visitors is limited as well as time of the visit. Tourists can touch the animals, take pictures, and even 
interact with the animals in the water through a submersible platform. Nevertheless, swimming with the porpoises is not permitted.

Romagnoli (2009) states that the Flutuante dos Botos receives an average of 250 visitors per week. The visit to the Flutuante is included on cruise ships and hotel tours, however the experience is open to any type of visitor independent of a tourism package. It should be mentioned that the Amazonian dolphins or botos are of cultural importance to the people of the Amazon. They are myths in folktales told for generations, where it is said that the dolphin turns into a man and impregnates young women in the village.

\section{Survey Instrument}

The survey instrument used in this thesis is the third improved version designed and implemented by the WVU Recreation Research team in the Amazon. The survey instrument followed some of the NVUM (National Visitor Use Monitoring) guidelines regarding its structure and type of questions. NVUM can be defined as a permanent sampling system for assessing visitor's characteristics, measuring use, as well as satisfaction with the National Forest systems of recreation opportunities (Kocis et al., 2004). This framework is well known among US park and forest managers. The original survey contained 36 questions including open-ended questions. For this study's purpose, 24 questions were selected. These questions included demographic information, trip characteristics, satisfaction items, motivation, and crowding. The survey instrument was originally created in English and then translated and made available in three other languages including Portuguese, Spanish, and French.

In the sociodemographic set of questions, visitors were asked about gender, age, country of residence (if Brazilians, state and city of origin), and education level. Group characteristics included questions regarding the number of adults and children per group, type of group, and 
group composition. For trip characteristics, visitors responded to questions about trip planning, length of the visit, frequency of which they visit the area, transportation mode, activities participated in, and primary activity. The satisfaction portion of the survey included two questions, the first one assessing the visitors' overall satisfaction with the area, and the second one rating the quality of specific items such as facilities, safety and security, trail condition, cleanliness of the area, interpretation, and access roads (See Appendix). Visitors had a not applicable option for items that did not apply to their recreation experience. A 5-point Likert scale ( $1=$ poor, $5=$ excellent (Likert, 1932) was used to measure overall satisfaction as well as satisfaction level for each item. The main motivation of the recreationists visiting the area was assessed through a single selection type of question.

The last section of the survey assessed visitors' perception related to crowding and measures the positive and negative impacts on visitors. A common scale used in recreation to measure crowding is a 9-point Likert scale $(1=$ not at all crowded, $9=$ extremely crowded $)$ designed by Heberlein and Vaske (1977). This scale has been used in previous versions of the survey instrument; it revealed that the vast majority of the visitors reported not at all crowded (Burns \& Moreira, 2015). Subsequently, a different need arose: to measure the extent of positive and negative impacts of visitor experience. Changes to this question were made in order to investigate this potential cultural phenomenon. The decision of adapting this question to a more specific context was driven by the need to provide managers with detailed insight about their conservation units. Burns \& Moreira (2017) emphasized the importance of resource managers to consider the uniqueness, as well as the impacts of spatial and temporal variables in their area when making a decision on public use. That way, a 9-point negative and positive scale $(-4=$ reduced my enjoyment, $0=$ no effect, $4=$ enhanced my enjoyment) was applied to encompass 
the concepts of crowding and functional density in the study areas (Burns \& Moreira, 2015).

This scale presents results that are fundamental for the development of this work.

\section{Data Collection}

The data presented in this thesis was selected from a WVU Brazil Recreation Database that contains over 10,000 surveys collected in different units in Brazil since 2014. This data collection was the result of a visitor monitoring effort intended to replicate and extend a US Forest Service approach, the NVUM. According to Burns \& Moreira (2017), this method of collecting visitor use data was the first ever to be applied in a protected area in Brazil.

The cutoff dates set for this study were October 2015 - June 2016 for both Tapajós NF and Anavilhanas NP. Different versions of surveys have been applied in the three years of research. The cutoff date of October 2015 was chosen to match up with the publication of the most recent survey instrument. A total of six interviewers were involved in the data collection process, three for each site. Methodology consisted of face-to-face interviews conducted with electronic tablets. Some of the advantages of face-to-face interviews include the possibility of further explanation of and repetition of questions if needed in order to overcome any language barriers (Berg \& Lune, 2004). Through the use of electronic tablets and the DroidSurvey application, data was collected and stored until uploaded via Wi-Fi to an online platform, then downloaded into an SPSS (Statistical Packages for the Social Sciences) database for further analyses. Besides facilitating the management of the data and streamlining data processing, this digital approach diminishes the amount of printed material. Interview sites were selected according to the flow of visitors. In the Tapajós, data was collected in the three gateway locations to the Forest, São Domigos, Maguari, and Jamaraquá on strategic points. At the Anavilhanas site, interviews were conducted in an area known as Flutuante dos Botos, where 
daily tours stop to let visitors view and touch dolphins from a floating platform. This setting is also an entry and exit point of tours to the Park. In both locations, visitors were interviewed at the end of their experience in the park/forest. The survey days were spread across weekdays, weekends and different holidays.

The total of number of usable data points from the two areas of study used in this thesis is 2534 surveys (See table below).

Table 1: Surveys per Study Area

\begin{tabular}{ccc}
\hline Area & \# of surveys & Total \# of surveys \\
\hline Anavilhanas National Park & 1277 & \\
Tapajós National Forest & 1257 & 2534 \\
\hline
\end{tabular}

\section{Testing of the Research Questions}

The Brazil Recreation Database is structured in SPSS format for data analyses. For this thesis, a new SPSS database was created containing data only from the cutoff dates. The database was then cleaned and set according to the survey questions selected for this study. The research questions were addressed through the following analyses:

RQ1: What is the visitor profile of people visiting the Tapajós National Forest and Anavilhanas National Park - Amazon Brazil?

Table 2: Variables \& Statistics

\begin{tabular}{lll}
\hline & \multicolumn{1}{c}{ Variable } & \multicolumn{1}{c}{ Statistic } \\
\hline 1.1 Socio demographics & Gender & Frequencies \& Valid Percent \\
& Age & Frequencies \& Means \\
& Education & Frequencies \& Valid Percent \\
& Country & Frequencies \& Valid Percent \\
& State and City of residence & Frequencies \& Valid Percent \\
& Number of adults & Means \\
& Number of children & Means \\
& Group composition & Frequencies \& Valid Percent \\
1.3 Trip characteristics & Trip planning & Frequencies \& Valid Percent
\end{tabular}


First/repeat visit

Year of first visit

Visits per year

Overnight/day visitors

Length of stay

Transportation mode

Activities participated

Primary activity

1.4 Reason for visit

1.5 Satisfaction

1.6 Crowding

Service quality
Primary reason for visit

Overall satisfaction
Frequencies \& Valid Percent Means

Means

Frequencies \& Valid Percent Means

Frequencies \& Valid Percent

Frequencies \& Valid Percent

Frequencies \& Valid Percent

Frequencies \& Valid Percent

Frequencies, Valid Percent \&

Means

Effect of number of people
Valid Percent \& Means

Frequencies, Means

RQ1.1: Are there differences between Tapajós and Anavilhanas visitors?

Cross tabulations, chi-square, and independent samples t-tests were conducted to examine differences between visitors in the two areas.

RQ2: Is there a relationship between crowding and visitors' satisfaction in the overall sample?

Simple linear regression was conducted to understand how the independent variable perceived crowding interacts with the dependent variable overall satisfaction.

RQ2.1: Do age, gender, and frequency of visit affect perceived crowding on overall sample?

Multiple linear regression was applied to determine whether the independent variables age, gender, and frequency of visit influence perceived crowding. 


\section{CHAPTER 4}

\section{RESULTS}

In this chapter, the results of the statistical analyses are presented and described according to their corresponding research question. The first section contains data from the overall sample of respondents. Results were summarized in tables including frequencies, valid percentages, and means. The second section presents the results of analyses regarding differences on the profile of respondents between the two protected areas. For this section, to determine whether or not there were differences in the mean scores, Chi-Square tests were used. For comparing the valid percentages, cross tabulation analyses were conducted. Valid percentages, means, Chi-Square, degrees of freedom, $p$ and $t$ values were reported in the tables. The third and fourth section of this thesis shows the results of Pearson's correlations and regression analyses conducted in order to understand the relationship between variables.

\section{RQ1: What is the visitor profile of people visiting the Tapajós National Forest and}

\section{Anavilhanas National Park - Amazon Brazil?}

Tables 3 and 4 show the results of the descriptive analyses of the sociodemographic variables. Frequencies and valid percentages were calculated for the following variables: country, country of origin, Brazilian state and city, gender, and education level. The mean value was calculated for respondent age.

Most of the respondents were from Brazil (83.5\%) while less than one-fifth were from a foreign country $(16.5 \%)$. Of the Brazilian respondents, visitors were from three main states: Amazonas (27.6\%), Pará (22.3\%) and São Paulo (22.1\%). The results show that one-fourth 
$(25.4 \%)$ of the respondents came from the city of Manaus, while the other third $(33.3 \%)$ were distributed within the cities of São Paulo (17.9\%) and Santarém (15.4\%). Of the international respondents, the majority were from United States (29.8\%) followed by Germany (20.2\%), France (16.7\%), and the United Kingdom (15.1\%). Other popular countries included Argentina and Switzerland with a total $17.9 \%$ of the respondents.

Table 3: Sociodemographic Profile of Respondents

\begin{tabular}{lcc}
\hline & Frequencies & Valid Percent \\
\hline Country & & \\
Brazil & 2115 & 83.5 \\
Foreign country & 419 & 16.5 \\
Country of origin & & \\
United States & 77 & 29.8 \\
Germany & 52 & 20.2 \\
France & 43 & 16.7 \\
United Kingdom & 39 & 15.1 \\
Argentine & 27 & 10.5 \\
Switzerland & 19 & 7.4 \\
State & & \\
Amazonas & 584 & 27.6 \\
Pará & 471 & 22.3 \\
São Paulo & 467 & 22.1 \\
Rio de Janeiro & 178 & 8.4 \\
City & & \\
Manaus & 536 & 25.4 \\
São Paulo & 378 & 17.9 \\
Santarém & 326 & 15.4 \\
Rio de Janeiro & 158 & 7.5 \\
\hline
\end{tabular}

A little over half of the respondents $(53.3 \%)$ were female, and the average age of the recreationists was nearly 39 years (38.50). The breakdown of education level was as follows: over half of the respondents $(65.9 \%)$ were highly educated, holding either a college or a graduate degree; less than one-fourth (18.3\%) answered that they have not completed college; and $15.8 \%$ reported to have completed elementary school or obtained a high school diploma. 
Table 4: Sociodemographic Profile of Respondents

\begin{tabular}{lccc}
\hline & Frequencies & Valid Percent & Mean \\
\hline Gender & & & \\
Female & 1350 & 53.3 & 38.50 \\
Male & 1182 & 46.7 & \\
Age & & & \\
Education & 39 & 1.5 & \\
Elementary & 361 & 14.3 & \\
High school & 464 & 18.3 & \\
Some college & 898 & 35.5 & \\
College graduate & 770 & 30.4 & \\
Post graduate & &
\end{tabular}

Table 5 presents information about the groups visiting the two protected areas in the Amazon. The average number of adults in a group was five (mean=4.93) and for the groups with children, the average number of children per group was two (mean=2.25). Nearly three-fourths of the respondents reported to not have children in their group. Regarding group composition, family groups were the most popular and corresponded to over one-fourth (28.0\%) of the interviewees followed by groups of friends (22.3\%). Couples and mixed groups composed of family and friends were also commonly represented with $19.1 \%$ and $13.5 \%$ of the respondents respectively. A small percentage (6.9\%) of the visitors reported traveling alone. Altogether, commercial groups, education, and organized groups comprised $11.9 \%$ of the groups visiting the areas.

Table 5: Group characteristics of Respondents

\begin{tabular}{lccc}
\hline & Frequencies & Valid Percent & Mean \\
\hline Number of adults & & & 4.93 \\
Number of children & & & 2.25 \\
Group Composition & 676 & 28.0 & \\
Family & 537 & 22.3 & \\
Friends & 462 & 19.1 & \\
Couple & 325 & 13.5 & \\
Family and Friends & 167 & 6.9 & \\
Alone & 118 & 4.9 & \\
Commercial group & &
\end{tabular}


Education $\quad 62 \quad 2.6$

Organized group $\quad 50 \quad 2.1$

Other

$16<1.0$

The three following tables present the variables of the study related to trip characteristics of the respondents. The results show that over one-third of the visitors (40.8\%) made their decision to visit the areas either on the same day of the visit or spent between 2-3 days planning their trip. Less than one-fifth of respondents (16.0\%) said they spent 4 to 14 days planning. Over one-third (30.2\%) of the respondent's answers concentrated on 15 days to 3 months of trip planning.

The vast majority (84.6\%) of respondents were first-time visitors while only $15.4 \%$ were repeat visitors. Of those returning to the areas, the mean obtained for the year of their first visit was 2009 (mean=2009.68). Over half of the visits $(53.7 \%)$ were day visits with a length of stay of approximately 6 hours (mean= 5.55). Overnight visits represented $46.3 \%$ of the sample and the average length of stay of those were four days.

Table 6: Trip characteristics of Respondents

\begin{tabular}{|c|c|c|c|}
\hline & Frequencies & Valid Percent & Mean \\
\hline \multicolumn{4}{|l|}{ Trip planning } \\
\hline Today & 401 & 15.8 & \\
\hline 2 - 3 days & 634 & 25.0 & \\
\hline 4 - 7 days & 264 & 10.4 & \\
\hline $8-14$ days & 142 & 5.6 & \\
\hline 15 days -1 month & 328 & 13.0 & \\
\hline 1- 3 months & 384 & 15.2 & \\
\hline More than 3 months & 379 & 15.0 & \\
\hline First time visitors & 2143 & 84.6 & \\
\hline Repeated visitors & 389 & 15.4 & \\
\hline Year of first visit & & & 2009.68 \\
\hline Day visit & 1358 & 53.7 & \\
\hline Length of stay & & & 5.55 \\
\hline Overnight visit & 1173 & 46.3 & \\
\hline Length of stay & & & 4.09 \\
\hline
\end{tabular}


Among the top three modes of transportation used by the visitors, over one-third $(42.4 \%)$ of respondents opted for land transportation, while one-fourth $(27.6 \%)$ used water vehicles - i.e. speedboat and sailboat. Other transportation modes reported by the visitors included rental cars and public or private buses.

Table 7: Trip characteristics of Respondents Continued.

\begin{tabular}{lcc}
\hline & Frequencies & Valid Percent \\
\hline Transportation mode & & \\
Private car & 1075 & 42.4 \\
Speedboat & 362 & 14.3 \\
Boat & 315 & 12.4 \\
Rental car & 251 & 9.9 \\
Public bus & 190 & 7.5 \\
Private bus & 110 & 4.3 \\
Taxi & 98 & 3.9 \\
Motorcycle & 60 & 2.4 \\
On foot & 43 & 1.7 \\
Airplane & 37 & 1.5 \\
Other & 15 & $<1.0$ \\
\hline
\end{tabular}

Respondents participated in a range of activities during their visit to the areas; Table 8 lists the main activities that the respondents participated in. The most popular activity was swimming (57.9\%), followed by viewing wildlife (53.0\%), and having a lunch/picnic (50.3). Other activities such as hiking (49.7\%), boating/canoeing (48.1\%), and buying crafts $(31.3 \%)$ were also common activities among the recreationists. In this question visitors were allowed to pick as many activities as they had participated in.

Table 8: Trip characteristics of Respondents Continued

\begin{tabular}{lcc}
\hline & Frequencies & Valid Percent \\
\hline Activities & & \\
Swimming & 1466 & 57.9 \\
Viewing wildlife & 1344 & 53.0 \\
Lunch/Picnic & 1274 & 50.3 \\
Hiking & 1259 & 49.7 \\
Boating/Canoeing & 1220 & 48.1
\end{tabular}


Buying crafts

Visiting community area

Visiting a famous attraction

Barbeque

Camping

Viewing waterfalls

Other activity
793

749

277

184

122

147

65
31.3

29.6

10.9

7.3

4.8

5.8

2.6

As an extension of the previous question, respondents were asked to indicate their primary activity. Visitors were presented with the same range of activities of the previous question but this time the question had a single-selection format. The top three activities reported were viewing wildlife with almost one-third (29.7\%) of the visitors selecting this option. The other primary activities were hiking (24.4\%) followed by swimming (10.5\%).

Table 9: Trip Characteristics of Respondents Continued

\begin{tabular}{lcc}
\hline & Frequencies & Valid Percent \\
\hline Primary Activities & & \\
Viewing wildlife & 462 & 29.7 \\
Hiking & 379 & 24.4 \\
Swimming & 163 & 10.5 \\
Visiting a famous attraction & 130 & 8.4 \\
Boating/canoeing & 91 & 5.9 \\
Other activity & 155 & 10.0 \\
\hline
\end{tabular}

In terms of the primary reason for the visit, nearly half (48.4\%) of the respondents selected an option connected to a personal characteristic, such as: I enjoy nature. Almost onefourth $(24.7 \%)$ opted for an option associated to a characteristic of the place Good place to experience culture. A number of people visited the areas for social reasons such as spending time with family and friends (10.1\%). Less common reasons for visiting were those related to personal connections with the place, activity driven reasons, or proximity.

Table 10: Reason for visit of Respondents

Frequencies $\quad$ Valid Percent




\begin{tabular}{lll}
\hline Primary reason for visit & 1111 & 48.4 \\
$\quad$ I enjoy nature. & 568 & 24.7 \\
$\quad$ Good place to experience & 231 & 10.1 \\
$\begin{array}{l}\text { culture. } \\
\quad \text { Want to spend time with }\end{array}$ & 215 & 9.4 \\
family/friends. & 131 & 5.7 \\
$\quad$ Ilike the place itself. & 39 & 1.7 \\
$\quad$ It is a good place to do the & & \\
outdoor activities that I like. & & \\
It is close home. &
\end{tabular}

The survey also assessed the level of recreationist satisfaction. Over half of the respondents $(66.7 \%)$ rated their visit as either excellent or perfect. A group of nearly one-third $(30.1 \%)$ evaluated their satisfaction level as either good or very good. Only a few respondents (3.2\%) rated their visit as poor or fair. On a 6-point scale (poor= 1 and perfect=6), the mean rate for overall satisfaction was 4.80 .

Table 11: Satisfaction of Respondents

\begin{tabular}{lccc}
\hline & Frequencies & Valid Percent & Mean \\
\hline Overall satisfaction & & & \\
Poor & 30 & 1.3 & \\
Fair & 43 & 1.9 & 4.80 \\
Good & 232 & 10.0 & \\
Very good & 465 & 20.1 & \\
Excellent & 814 & 35.2 & \\
Perfect & 727 & 31.5 & \\
& & & \\
\hline
\end{tabular}

In addition to the overall satisfaction question, recreationists were asked to evaluate the quality of single items of their trip. In this question the option not applicable was available and the percentages were excluded from the mean. The item trail condition was rated with the highest mean (4.16) followed by safety and security (4.04). The items access roads and environmental interpretation were rated with the lowest means, (3.36) and (3.51), respectively. 
The domains cleanliness of area and facilities were equally rated (mean=3.83) with medium satisfaction level.

Table 12: Satisfaction of Respondents Continued

\begin{tabular}{lccccccc}
\hline & Poor & Fair & Good $\begin{array}{c}\text { Very } \\
\text { Good } \\
\text { Quality Domain }\end{array}$ & & \multicolumn{5}{c}{$\begin{array}{c}\text { Excellent } \\
\text { Valid Percent }\end{array}$} & $\begin{array}{c}\text { Not } \\
\text { Applicable }\end{array}$ \\
\hline $\begin{array}{c}\text { Cleanliness of } \\
\text { area }\end{array}$ & $<1.0$ & 5.9 & 33.8 & 26.7 & 31.7 & 1.0 & 3.83 \\
$\begin{array}{c}\text { Safety and } \\
\text { security }\end{array}$ & $<1.0$ & 3.1 & 26.0 & 32.1 & 37.1 & 1.4 & 4.04 \\
$\begin{array}{c}\text { Trail condition } \\
\text { Facilities }\end{array}$ & $<1.0$ & 1.6 & 13.5 & 20.6 & 27.3 & 36.3 & 4.16 \\
$\begin{array}{c}\text { Access roads } \\
\begin{array}{c}\text { Environmental } \\
\text { interpretation }\end{array}\end{array}$ & 7.6 & 12.6 & 30.8 & 28.7 & 17.1 & 3.2 & 3.36 \\
$\begin{array}{c}\text { (panels, guides, } \\
\text { brochures, etc.) }\end{array}$ & 6.5 & 11.0 & 28.6 & 25.0 & 23.6 & 5.2 & 3.51 \\
\hline
\end{tabular}

As mentioned earlier, a 9-point negative and positive scale was created to better understand the extent of negative and positive impacts of other people on the recreationist's experience. Table 13 shows that few visitors $(6.5 \%)$ reported to be negatively impacted by the presence of others; of those, $3.9 \%$ reported that seeing others reduced their enjoyment. Less than one-fourth (22.6\%) indicated that seeing others had no effect on their visit. Nearly three-fourths of respondents $(70.0 \%)$ reported a positive impact caused by the presence of others. Of those, over one-third (34.3\%) said that seeing others enhanced their enjoyment.

Table 13: Respondents Perceptions of Crowding

\begin{tabular}{lccc}
\hline & Frequencies & Valid Percent & Mean \\
\hline $\begin{array}{l}\text { Impact of others } \\
\begin{array}{l}-4 \text { Reduced my } \\
\text { enjoyment }\end{array}\end{array}$ & 90 & 3.9 & \\
\end{tabular}




\begin{tabular}{llll}
\cline { 2 - 3 }-3 & & $<1.0$ & \\
-2 & 28 & 1.2 & \\
-1 & 25 & 1.1 & 7.05 \\
0 No effect & 516 & 22.6 & \\
1 & 123 & 5.4 & \\
2 & 239 & 10.5 & \\
3 & 474 & 20.7 & \\
4 Enhanced my & 784 & 34.3 & \\
enjoyment & & & \\
\hline
\end{tabular}

\section{RQ1.1: Are there differences between Tapajós and Anavilhanas visitors?}

Cross tabulation, chi-square, and independent samples t-tests were conducted in order to analyze the overall significant differences between recreationists of the Tapajós National Forest and Anavilhanas National Park. The questions selected for analyses pertained to sociodemographic, group and trip characteristics, visit reason, satisfaction, and crowding. Findings were reported in tables containing valid percentages, Person's Chi-Square values, and degrees of freedom, and $t$ values.

Table 14 shows the results of comparison of the variable country of origin. A crosstabulation analysis through the use of Person's Chi-Square test shows that there was no significant difference regarding the percentage of national and international visitors recreating in the two locations $\left(\mathrm{x}^{2}=1.346, \mathrm{df}=1, \mathrm{p}>.05\right)$. The Tapajós National Forest and the Anavilhanas National Park received a similar range of national and international visitors as confirmed in the table below.

Table 14: Results of Comparison of Sociodemographic

\begin{tabular}{lccc}
\hline & Tapajós & Anavilhanas \\
& $\%$ & $\%$ & \\
\hline Country & & & $\mathrm{x}^{2}=1.346$ \\
Brazil & 84.3 & 82.6 & $\mathrm{df}=1$ \\
Foreign country & 15.7 & 17.4 & $\mathrm{p}=.246$ \\
\hline
\end{tabular}


Table 15 shows the results of analyses of the variables gender, age, and education level. With respect to gender distribution, the percentage of male and female visitors did not differ by location $\left(\mathrm{x}^{2}=2.853, \mathrm{df}=1, \mathrm{p}>.05\right)$. In both locations, the percentage of female visitors was slightly higher compared to males. In regards to the average age of the visitors, a significant difference was found $(\mathrm{t}=4.77, \mathrm{p}<.001)$. The results show that Tapajós visitors tend to be slightly younger $(M=37.26, \mathrm{SD}=13.7)$ than Anavilhanas visitors $(\mathrm{M}=39.80, \mathrm{SD}=12.9)$. When considering the highest education level reported by the respondents, a chi-square test revealed significant differences $\left(\mathrm{x}^{2}=134.038, \mathrm{df}=4, \mathrm{p}<.001\right)$. Tapajós visitors received more people with some college education (24.3\%) while Anavilhanas received more people possessing a high school level of education (20.8\%). However, over half of the respondents in both locations were highly educated holding either a college or a post graduate degree as shown in Table 26.

Table 15: Results of Comparison of Sociodemographic Continued

\begin{tabular}{|c|c|c|c|}
\hline & $\begin{array}{c}\text { Tapajós } \\
\%\end{array}$ & $\begin{array}{c}\text { Anavilhanas } \\
\%\end{array}$ & \\
\hline Gender & & & $x^{2}=2.853$ \\
\hline Males & 48.4 & 45.0 & $\mathrm{df}=1$ \\
\hline Females & 51.6 & 55.0 & n.s. \\
\hline \multicolumn{4}{|l|}{ Age } \\
\hline & & & \\
\hline & 37.26 & 39.80 & $\mathrm{t}=4.77 * * *$ \\
\hline \multicolumn{4}{|l|}{ Education } \\
\hline Elementary & $<1.0$ & 2.2 & $x^{2}=134.038$ \\
\hline High school & 7.6 & 20.8 & $\mathrm{df}=4$ \\
\hline Some college & 24.3 & 12.4 & $\mathrm{p}<.001$ \\
\hline College graduate & 35.8 & 35.1 & \\
\hline Post graduate & 31.3 & 29.5 & \\
\hline
\end{tabular}

In an analysis of group characteristics, a significant difference $(\mathrm{t}=-6.854 ; \mathrm{p}<.001)$ was noted in the number of adults per group visiting Tapajós and Anavilhanas. Tapajós visitors recreated in larger groups $(M=5.79, \mathrm{SD}=6.805)$ than Anavilhanas visitors $(\mathrm{M}=4.08, \mathrm{SD}=$ 
5.650). In regards to the number of children per group, no significant difference was found $(\mathrm{t}=$ $6.638 ; \mathrm{p}>.05)$ between Tapajós $(\mathrm{M}=2.61, \mathrm{SD}=2.428)$ and Anavilhanas $(\mathrm{M}=2.10, \mathrm{SD}=$ 2.073). Group characteristics were further analyzed in terms of group composition. As can been seen in Table 16, there are significant differences in group composition $\left(\mathrm{x}^{2}=265.089 ; \mathrm{df}=8 ; \mathrm{p}<\right.$ $.001)$. Most of the Anavilhanas groups were composed of family members (37.0\%) while Tapajós groups were composed of friends. Also, when compared to Tapajós, couples were more common visitors to the Anavilhanas National Park.

Table 16: Results of Comparison of Group Characteristics

\begin{tabular}{|c|c|c|c|c|}
\hline & Tapajós & & Anavilhanas & \\
\hline & & Mean & & \\
\hline Number of adults & 5.79 & & 4.08 & $\begin{array}{c}\mathrm{t}=- \\
6.854 * * *\end{array}$ \\
\hline Number of children & 2.61 & & 2.10 & $\begin{array}{c}\mathrm{t}=- \\
6.638 \text { n.s. }\end{array}$ \\
\hline \multicolumn{5}{|l|}{ Group composition } \\
\hline & & $\%$ & & \\
\hline Alone & 8.7 & & 5.1 & \\
\hline Couple & 12.7 & & 25.6 & \\
\hline Family & 19.0 & & 37.0 & \\
\hline Friends & 29.5 & & 15.0 & $x^{2}=$ \\
\hline Family and & 17.5 & & 9.5 & 265.089 \\
\hline \multicolumn{5}{|l|}{ Friends } \\
\hline Commercial group & 6.2 & & 3.6 & $\mathrm{p}<.001$ \\
\hline Organized group & 1.3 & & 2.8 & \\
\hline Education & 4.4 & & $<1.0$ & \\
\hline Other & $<1.0$ & & $<1.0$ & \\
\hline
\end{tabular}

Table 17 shows a comparative analysis of questions pertaining to respondent trip characteristics. Starting with trip planning, the results revealed significant differences $\left(\mathrm{x}^{2}=\right.$ 193.591; $\mathrm{df}=6 ; \mathrm{p}<.001)$. Anavilhanas visitors spent more time planning their trip to the Park, (more than three months), while Tapajós visitors took only 2-3 days preparing their visit to the National Forest. Respondents of both locations were asked whether they were first time visitors; 
no significant differences were found $\left(x^{2}=1.784 ; \mathrm{df}=1 ; \mathrm{p}>.05\right)$. The majority of the respondents in both areas were first-time visitors as presented in the table below. Further analyses were conducted in order to better understand the profile of repeated visitors. Tapajós and Anavilhanas repeat visitors differ in the year of their first visit to the Forest/Park $(\mathrm{t}=-3.563$; $\mathrm{p}<.001)$. Tapajós repeat visitors are relatively newer $(\mathrm{M}=2010.93 ; \mathrm{SD}=6.463)$, compared to Anavilhanas repeat visitors $(\mathrm{M}=2008.60 ; \mathrm{SD}=6.17)$. The variables day visit and overnight visit were also analyzed between the two study areas. Tapajós visitors were more likely to visit the Forest on day trips (70.7\%), while conversely, Anavilhanas visitors (63.2\%) were more likely to be overnight visitors $\left(x^{2}=292.600 ; \mathrm{df}=1 ; \mathrm{p}<.001\right)$. Closely examining the duration of overnight visits, significant differences were found $(\mathrm{t}=5.420 ; \mathrm{p}<.001)$. Anavilhanas visitors spent more days recreating in the park $(\mathrm{M}=4.62 ; \mathrm{SD}=5.740)$, while Tapajós visitors were more likely to remain in the Forest for fewer days $(\mathrm{M}=2.91 ; \mathrm{SD}=2.671)$. Regarding day trip duration, Tapajós visitors reported spending more hours in the park $(\mathrm{M}=6.19 ; \mathrm{SD}=2.152)$ than Anavilhanas visitors $(\mathrm{M}=4.35 ; \mathrm{SD}=2.724)(\mathrm{t}=-13.666 ; \mathrm{p}<.001)$.

Table 17: Results of Comparison of Trip Characteristics

\begin{tabular}{|c|c|c|c|}
\hline & $\begin{array}{c}\text { Tapajós } \\
\%\end{array}$ & $\begin{array}{c}\text { Anavilhanas } \\
\%\end{array}$ & \\
\hline \multicolumn{4}{|l|}{ Trip planning } \\
\hline Today & 17.7 & 14.0 & \multirow{7}{*}{$\begin{array}{c}\mathrm{x}^{2}=193.591 \\
\mathrm{df}=6 \\
\mathrm{p}<.001\end{array}$} \\
\hline 2 - 3 days & 30.0 & 20.2 & \\
\hline 4 - 7 days & 9.5 & 11.3 & \\
\hline $8-14$ days & 5.9 & 5.3 & \\
\hline 15 days -1 month & 17.0 & 8.9 & \\
\hline $1-3$ months & 13.6 & 16.7 & \\
\hline More than 3 & 6.3 & 23.5 & \\
\hline \multicolumn{4}{|l|}{ months } \\
\hline First time visitors & 85.6 & 83.7 & $x^{2}=1.784$ \\
\hline Repeated visitors & 14.4 & 16.3 & $\begin{array}{c}\mathrm{df}=1 \\
\mathrm{p}=.182\end{array}$ \\
\hline \multicolumn{4}{|c|}{ Mean } \\
\hline Year of first visit & 2010.93 & 2008.60 & $\mathrm{t}=-3.563 * * *$ \\
\hline
\end{tabular}




\begin{tabular}{|c|c|c|c|}
\hline \multirow{2}{*}{$\begin{array}{l}\text { Day visit } \\
\text { Overnight visit }\end{array}$} & 70.7 & 36.8 & $x^{2}=292.600$ \\
\hline & 29.3 & 63.2 & $\begin{array}{c}\mathrm{df}=1 \\
\mathrm{p}<.001\end{array}$ \\
\hline Length of stay & 6.19 & 4.35 & $\mathrm{t}=-13.666 * * *$ \\
\hline $\begin{array}{l}\text { Length of stay } \\
\text { (days) }\end{array}$ & 2.91 & 4.62 & $\mathrm{t}=5.420 * * *$ \\
\hline
\end{tabular}

The next table shows the results of an analysis of the primary reason for visiting the Forest/Park. No significant differences were found $\left(x^{2}=17.343 ; \mathrm{df}=5 ; \mathrm{p}>.05\right)$. The majority of both Tapajos and Anavilhanas visitors reported the same primary reasons for visiting the areas. The options I enjoy nature, and It is a good place to experience culture had the highest percentage of respondents. The other options were also reported with similar percentages for both areas.

Table 18: Results of Comparison of Reason for Visit

\begin{tabular}{lccc}
\hline & $\begin{array}{c}\text { Tapajós } \\
\%\end{array}$ & $\begin{array}{c}\text { Anavilhanas } \\
\%\end{array}$ & \\
& & & \\
\hline Primary reason for visit & 48.6 & 48.2 & \\
$\quad$ I enjoy nature. & 23.9 & 25.6 & $\mathrm{x}^{2}=17.343$ \\
Good place to & & 10.6 & $\mathrm{df}=5$ \\
$\begin{array}{l}\text { experience culture. } \\
\text { Want to spend time }\end{array}$ & 9.5 & 9.9 & $\mathrm{p}=.004$ \\
with family/friends. & & 5.0 & \\
$\begin{array}{l}\text { I like the place itself. } \\
\text { It is a good place to }\end{array}$ & 6.8 & & \\
$\begin{array}{l}\text { do the outdoor } \\
\text { activities that I like. }\end{array}$ & & $<1.0$ & \\
It is close home. & 2.7 & & \\
\hline
\end{tabular}

For analyzing differences in trip satisfaction across both locations, an independent sample $\mathrm{t}$-test was applied to compare the means. A significant difference was noted $(\mathrm{t}=-10.393 ; \mathrm{p}<$ .001), with Tapajós visitors more likely to report the highest level (excellent) of satisfaction with 
their trip; conversely, Anavilhanas visitors were more likely to rate the overall level of satisfaction with their trip as good or very good.

Table 19: Results of Comparison of Satisfaction

\begin{tabular}{|c|c|c|c|c|}
\hline & $\begin{array}{c}\text { Tapajós } \\
\%\end{array}$ & & $\begin{array}{c}\text { Anavilhanas } \\
\%\end{array}$ & \\
\hline \multicolumn{5}{|c|}{ Overall satisfaction } \\
\hline Poor & $<1.0$ & & 2.3 & \\
\hline Fair & 1.3 & & 2.4 & \\
\hline Good & 6.4 & & 13.2 & \\
\hline Very good & 16.3 & & 24.0 & \\
\hline Excellent & 35.6 & & 34.8 & \\
\hline \multirow[t]{3}{*}{ Perfect } & 39.5 & & 23.4 & \\
\hline & & Mean & & \\
\hline & 5.04 & & 4.57 & $\mathrm{t}=-10.393 * * *$ \\
\hline
\end{tabular}

Further analyses of satisfaction focused on single items of the respondents' trip and their level of satisfaction. An independent sample t-test was conducted to compare the means for each item from both locations. As seen in Table 20, significant differences were found among all the items. Tapajós visitors reported to be more satisfied $(\mathrm{M}=3.91 ; \mathrm{SD}=958)$ with the item cleanliness of area than Anavilhanas visitors $(M=3.76 ; \mathrm{SD}=990)(\mathrm{t}=-3.775 ; \mathrm{p}<.001)$. Anavilhanas respondents were more likely to feel unsafe $(M=3.91 ; S D=941)$ while recreating in the area than Tapajós visitors $(\mathrm{M}=416 ; \mathrm{SD}=828)(\mathrm{t}=-6.562 ; \mathrm{p}<.001)$. For the respondents that participated in hiking activities, Tapajós visitors indicated higher level of satisfaction $(\mathrm{M}=$ 4.23; $\mathrm{SD}=840)$ with the trail conditions than Anavilhanas visitors $(\mathrm{M}=4,06 ; \mathrm{SD}=892)(\mathrm{t}=-$ 3.848; $\mathrm{p}<.001)$. In terms of facilities, Tapajós visitors, again, indicated higher level of satisfaction $(M=3.96 ; \mathrm{SD}=884)$ than the Anavilhanas ones $(\mathrm{M}=3.69 ; \mathrm{SD}=1.025)(\mathrm{t}=-6.374$; $\mathrm{p}<.001)$. The item access roads received the lowest mean in both areas $(\mathrm{M}=3.55, \mathrm{SD}=969$; $\mathrm{M}=3.17, \mathrm{SD}=1.275)$, however, Anavilhanas respondents indicated lower levels of satisfaction than Tapajós respondents $(\mathrm{t}=-8.002 ; \mathrm{p}<.001)$. The last item listed, environmental 
interpretation, was also low rated in both areas $(\mathrm{M}=3.63, \mathrm{SD}=1.085 ; \mathrm{M}=3.38, \mathrm{SD}=1.264)$ yet, Tapajós respondents were higher satisfied than respondents from Anavilhanas $(t=-4.737 ; p$ $<.001)$.

Table 20: Results of Comparison of Satisfaction Continued

\begin{tabular}{lccr}
\hline & Tapajós & Anavilhanas & \\
& & Mean & \\
\hline Quality Domain & & 3.76 & $\mathrm{t}=-3.775 * * *$ \\
Cleanliness of area & 3.91 & 3.91 & $\mathrm{t}=-6.562 * * *$ \\
Safety and security & 4.16 & 4.06 & $\mathrm{t}=-3.848 * * *$ \\
Trail condition & 4.23 & 3.69 & $\mathrm{t}=-6.374 * * *$ \\
Facilities & 3.96 & 3.17 & $\mathrm{t}=-8.002 * * *$ \\
Access roads & 3.55 & 3.38 & $\mathrm{t}=-4.737 * * *$ \\
Environmental & 3.63 & & \\
interpretation & & & \\
(panels, guides, & & & \\
brochures, etc.) & & & \\
\hline
\end{tabular}

Perceived crowding levels between Anavilhanas and Tapajós were examined and the results are show in Table 21. For this comparison, the crowding scale was recoded to a 9 point scale for comparing the means. In this case -4 (reduced enjoyment) corresponded to 1,0 to 5 (no effect), and 4 (enhanced enjoyment) to 9. The mean obtained was the same for both Tapajós and Anavilhanas, 7.05 ( $\mathrm{SD}=2.181 ; \mathrm{SD}=1.976$ respectively). A further comparison attested that there was not a significant difference in perceptions of crowding between the two samples. Visitors were somewhat positively affected by the presence of others and shared the same level of enjoyment.

Table 21: Results of Comparison of Perceptions of Crowding

\begin{tabular}{lcc}
\hline & $\begin{array}{c}\text { Tapajós } \\
\%\end{array}$ & $\begin{array}{c}\text { Anavilhanas } \\
\%\end{array}$ \\
\hline $\begin{array}{l}\text { Impact of others } \\
\begin{array}{l}-4 \text { Reduced my } \\
\text { enjoyment }\end{array}\end{array}$ & 5.3 & 2.6
\end{tabular}




\begin{tabular}{|c|c|c|c|}
\hline-3 & $<1.0$ & $<1.0$ & \\
\hline-2 & 1.2 & 1.2 & \\
\hline-1 & 1.3 & $<1.0$ & \\
\hline 0 No effect & 19.4 & 25.8 & \\
\hline 1 & 5.4 & 5.4 & \\
\hline 2 & 8.8 & 12.2 & \\
\hline 3 & 24.2 & 17.2 & \\
\hline \multirow{3}{*}{$\begin{array}{l}4 \text { Enhanced my } \\
\text { enjoyment }\end{array}$} & 34.1 & 34.5 & \\
\hline & & & \\
\hline & 7.05 & 7.05 & $t=-.049$ \\
\hline
\end{tabular}

\section{RQ2: Is there a relationship between crowding and visitors' satisfaction in the overall sample?}

First, a Pearson correlation analysis was conducted to determine whether or not perceived crowding and overall satisfaction were related. A small significant positive relationship was found $(\mathrm{r}=.160 ; \mathrm{p}<.001)$. Therefore, evidence suggested that the correlation observed does exist in the population. Similarly, a linear regression was conducted to understand the impact caused by other visitors on overall satisfaction. This analysis established that a statistically significant linear relationship existed between other visitors and respondent satisfaction $(\mathrm{F}(1,2285)=$ $59.899, \mathrm{p}<.0005)$. The impact caused by other visitors accounted for $2.5 \%$ of the variability in overall satisfaction.

Table 22: Results of Comparison of Crowding

\begin{tabular}{lcccc}
\hline & $\mathrm{r}$ & Beta & F-value & $\mathrm{R}^{2}$ \\
\hline Impact caused by others & .160 & .160 & 59.899 & .025 \\
\hline
\end{tabular}

\section{RQ2.1: Do age, gender, and frequency of visit affect perceived crowding on overall sample?}

A multiple regression analysis was applied to test whether age, gender, and first time vs repeat visitor's impact perceived crowding. The results show that these variables did not 
significantly predict the levels of perceived crowding found in the overall sample $(\mathrm{F}(3,2273)=$ $\left..462, \mathrm{p}=.709, \mathrm{R}^{2}=-.001\right)$.

\section{CHAPTER 5}

\section{DISCUSSION AND CONCLUSIONS}

The last chapter of this thesis presents a summary and discussion of the results of this study. Following management implications for protected areas in the Amazon Brazil are drawn. In another section suggestions for future research are proposed followed by the conclusions.

RQ1: What is the visitor profile of people visiting the Tapajós National Forest and Anavilhanas National Park - Amazon Brazil?

The profile of the respondents visiting the two protected areas in the Amazon consisted of highly educated Brazilians with an average age of 39 years. The percentage of females was slightly higher $(53.3 \%)$ than male visitors. This slightly difference can be either attributed to women's willingness to participate in surveys or a trend that indicates an increase in women's participation in outdoor activities. Almost two third of the visitors held a college degree or higher. The majority were national visitors, Brazilians $(83.5 \%)$ who came from the states of Amazonas (27.6\%), Pará (22.3\%), and São Paulo (22.1\%). The states of Amazonas and Pará are where the study areas are located. In this sense, proximity along with travel costs might have an influence on the high number of in-state visitors (Kinker, 2002). Although not geographically close to the study areas the state of São Paulo was well represented among visitors in the Amazon. This result is not a surprise since São Paulo is the most populated state of Brazil and also top ranked as place of origin for domestic trips in Brazil (Fundação Intituto de Pesquisas Econômicas, 2012). São Paulo is among the states of Brazil with highest income (Exame, 2017). 
In terms of group characteristics, visitors recreated in an average of five adults, most likely family members $(28.0 \%)$ or friends (22.3\%). These findings differ from a similar study conducted at the Tijuca National Park, Rio de Janeiro, in which groups were mainly composed of friends recreating in groups of $2-4$. There is a lack of studies reporting data on the number of groups with children, however this study shows that the majority (73.1\%) of the groups visiting the areas had no children. Additionally, attention should be given to the small percentage of visitors that reported to be part of an education, commercial, or organized group (total of 11.9\%). From this number it is possible to acknowledge the need that the Amazon region has for more tourism operators and others agencies/organizations offering competitive packages to leverage tourism in the region. While most of the tourism in Brazil takes place in the south and southeast Brazil; tourism operators in the Amazon are reduced in number and variety of packages (Ministério do Turismo, 2016).

Respondents took between 1- 3 days planning their trip to the forest/park (40.8\%). This result, along with data regarding the state of origin, suggests the prevalence of regional tourists. In general, visitors who come from further distances spend more time planning their trips. Over one third of the people interviewed said they spent between 1 to more than 3 months planning their trip. We hypothesize that these visitors were very likely to come from another region or even country. Surprisingly, the majority (84.6\%) of the respondents were first time visitors. On one hand, this is a positive sign and indicates the potential of the region to attract new visitors, on the other hand, it can be inferred that the low percentage of non-returning visitors might be due to a poor experience. The quality of a visitor's experience can interfere with the visitor's desire to return. A recent research conducted by the Ministry of Tourism during the Olympics (2016) in different parts of Brazil revealed that both national and international visitors demonstrated high 
interest in a returning trip to the country. This result is similar to others studies conducted in protected areas in which the desire of visitors to return is almost unanimous (WVU Recreation Research LAB, 2016; WVU Recreation Research LAB, 2015). However, this intention is not always fulfilled. A possible explanation for the Amazon case is the distance from major markets. Distant destinations often benefit most from longer length of stays and overnight expenditures but face challenges in attractiveness and accessibility resulting in less frequent repeat trips (Dupeyras and MacCallum, 2013). Slightly over half (53.7\%) of the visitors were on a day trip and spent an average of 6 hours. The other $46.3 \%$ were on overnight trips and stayed an average of 4 days recreating in the area. Length of stay of visitors is an important indicator of tourism's impact on local economy (Dupeyras \& MacCallum, 2013). In the case of distant destinations increasing repeat visits and length of stay is a continuous effort.

Visitors most commonly used private cars to get to the forest/park (42.4\%). Other modes of transportation via water such as speed boat (14.3\%) and boat (12.4\%) were also found to be a commonly used. Transportation plays an important role on the development of tourism (Palhares, 2003). The evolution of modes of transportation have changed the face of tourism and directly influences a visitor's decision on whether or not visit an area (Mammadov, 2012). Westlake and Robins (2005), enumerated a series of factors in choosing the transportation mode (e.g. time limit, distance, status, comfort, security, benefit, price, geographical position, competition). Understanding this transportation system enables the federal agency and stakeholders to keep the traffic of visitors organized while guaranteeing easy access and good services for either boat or car users.

Tourism activities can vary from one location to another according to the uniqueness of the natural setting. Recreationists visiting the two protected areas in the Amazon region reported 
have participated in swimming (57.9\%), viewing wildlife (53.0\%), lunch/picnic (50.3\%), hiking (49.7\%), boating/canoeing (48.1\%), and buying crafts (31.3\%). Among these activities, visitors pointed out viewing wildlife (29.7\%), hiking (24.4\%), and swimming (10.5\%) as primary activities. A 2006 analysis of visitation in national and state parks in Brazil revealed a potential of the Amazon region for water based activities exploring its hydrographic resource. The present study reinforces these findings. Viewing wildlife appears to be a popular and primary activity for tourists, which raises concerns in terms of how these activities have been conducted. This type of activity should be well regulated and monitored to ensure visitor's safety and minimum impact to wildlife. When developing tourism in a protected area it is crucial that managers have in mind the variety of users and the impact of an activity in that specific environment. Kinker (2002) emphasized that the type of recreationist visiting a protected area, along with length of stay, will depend on how well visitation has been managed in that area. Especially in the case of the Amazon, a sensitive biome, public use and management of visitors should be a priority for administrators.

Nearly half of the respondents (48.4\%) said they visited the area to be in contact with nature (I enjoy nature). The second main reason for visiting was attributed to a cultural component, (Good place to experience culture) (24.7\%). Vidal et al. (2013) found similar results in a study conducted at the ANP, nature or a combination of nature and culture were the main interest of the visitors. Besides the predominance of family members and friends on the composition of groups; time with family/friends was not one of main reasons bringing visitors to the areas. This study revealed that visitors may not perceive the areas as places for social gatherings with family and friends. Visitors also did not seem to have personal attachment to the areas. Activity driven reasons and proximity did not have a part in attracting visitors as well. 
Overall satisfaction levels in the study areas were somewhat high $($ mean $=4.80)$. This data along with the other studies that have found a high intention to return (Tapajós National Forest Interim Report, 2016; Anavilhanas National Park Interim Report, 2016) are an indication of competitiveness. The combination of high satisfaction and intention to return can be explored and converted into additional returning visits (Dupeyras and MacCallum, 2013). Using this information, managers, stakeholders, and marketers can tailor activities and campaigns focused on retaining these visitors. In terms of the quality of single items, visitors reported to be less satisfied with access roads (3.36) and environmental interpretation (3.51); these domains were rated with the lowest scores. The domains cleanliness of area (3.83) and facilities (3.83) received a little higher score. Visitors indicated high levels of satisfaction with the items trail condition (4.16) and safety and security (4.04). Contrary to overall satisfaction results that involves a series of subjective factors, managers have some control of service quality items (Lee, Graefe, and Burns, 2004). For instance, managers can take actions or make decisions to improve safety, access and other services.

As prior stated, the ANP and TNF have been exposed to intense tourism, which increases the chances of issues regarding environmental degradation, recreation conflict and crowding. The first two mentioned, although important, are not subject of this study. This work emphasizes crowding from a visitor's perspective, specifically looking at its effects on the quality of visitor's experience. The findings show that crowding is not an issue in the two protected areas in the Brazilian Amazon. In contrast, the 9-point scale used in this study revealed that visitors were positively impacted by seeing others (70.9\%) opposed to $6.5 \%$ that reported negative impact. A significant percentage of the interviewees (22.6\%) remained neutral. It is important to mention that the data collection sites were strategically selected according to the flow of visitors after 
recreating in the area. A similar study conducted in a state park in the south of Brazil assessed perceptions associated to specific number of people using the area at the same time. In all levels, negative impact was considered to be low (Garcia, 2015). These data differed from US based data (Vaske and Shelby, 2008) in which park visitors commonly reported a negative impact caused by the presence of others. According to the findings and based on literature, the concept of functional density was found to be the most appropriate for the Amazon scenario.

\section{RQ1.1: Are there differences between Tapajós and Anavilhanas visitors?}

Data collected was split by location and compared for significant differences. The findings show that even though access to the ANP is easier for foreign visitors compared to the TNF, the percentage of international visitors in both areas was similar. The ANP, different from the TNP has the advantages of been closer to a capital with an international airport. Besides the possibility of direct flights, the distance from the airport to the park is relatively short. These advantages impact travel cost making it cheaper and easier for internationals to visit the Anavilhanas Park. Considering all the apparent difficulties that international visitors would have to get to the TNF, a still significant number make their way there. This indicates that the TNF is somewhat competitive for international clientele.

In both locations the number of females was slightly higher. According to Dougherty et al. (2005) and Moutinho (2000) the number of females participating in outdoor recreation activities has increased. The findings of this study may point towards this trend present among visitors in the Amazon. If in future studies this number continues to go higher, this could have some effect on management of the area to better attend this demographic.

Tapajós visitors tend to be younger $(M=37.26)$ than Anavilhanas visitors $(M=39.80)$. Although a small difference, this information can be monitored and lead to the development of 
activities of interest for specific age range. Overall, Tapajós visitors were higher educated with $91.4 \%$ of interviewees holding at least a college degree compared to only $77 \%$ of Anavilhanas.

Tapajós visitors recreate in larger groups of $6(M=5.79)$, while Anavilhanas visitors prefer smaller groups of $4(M=4.08)$. This information is critical for designing tourism packages in both areas. It can also provide guidance on the designation of recreational areas to prevent resource damage. The number of children per group with children was an average of 2 and there was no difference between the two locations. Families and couples were more common among the recreationists visiting the ANP. The city of Novo Airão, near the park, already has an infrastructure to receive families, however the park itself lacks the minimum of structure and activities targeting groups of families. The preference on the Tapajós is for groups composed of friends which can be a more flexible type of group. Compared to Anavilhanas, the Tapajós received more commercial, organized, and education groups. The TNF has potential to receive these groups on the route for cruise ships in the Amazon. The Tapajos National Forest should be incorporated into this tourism route as one of the main attractions in Santarém.

Anavilhanas visitors spent more than three months planning their trip to the park while Tapajós visitors only needed 2-3 days to make their decision. This result was unexpected since both areas receive similar number of international visitors and that most of overall visitors come from the surrounding areas of the park/forest. In this case, what can be hypothesized/assumed is that the TNF itself may not be the main destination of the visitors. The Santarém region is well recognized as a freshwater beach destination in the Amazon, and once visitors are in Santarem it is easy to get to the forest without much planning. Conversely, Novo Airão and the ANP might have already developed a reputation as a primary destination and that would require more advance planning. 
The majority of visitors in both locations were first time visitors. This reflects the history of protected areas in Brazil and its most recent efforts to leverage tourism in those areas for economic benefit. Between the two areas, Anavilhanas is the one that has received repeat visitors for longer, since 2009 ( $M=2008.60)$. It is relevant to point out that exactly in that period October of 2008 - the status of the area was changed from Ecological Station to National Park open to the public. Most Tapajós repeat visitors reported to have visited the forest for the first time in $2011(\mathrm{M}=2010.93)$. Contrary to the ANP, the TNF since its creation in 1974, has been a National Forest with relatively more openness to public use. In this case, access might play an important role explaining this difference. Day visits are more common in the Tapajós opposed to Anavilhanas where most of the visits are overnight. Tapajós day visitors spend more hours (M= 6.19) in the area while Anavilhanas visitors tend to spend more days $(M=4.62)$. This difference can occur due to the proximity of Novo Airão to the park, visitors might not necessarily be staying in the park but in the region where the park is located. Often people mistake the limits of the ANP which is within to the city. On the Tapajós the situation is different, once the visitor is in the forest the closest urbanized area is within one-hour drive. Also, accommodations in the forest are limited to community houses. These factors may affect a visitor's decision on whether or not to spend more time in the area.

A trend was noticed in terms of reason for visit — in the two areas the visitors are looking for being in contact with nature and to experience culture. It can be implied from the results that there is an opportunity in both conservation units to implement education and interpretation programs as tools for increasing nature appreciation and awareness. There is also room for exploring cultural tourism highlighting the Amazon history and lifestyle of river communities. 
Overall satisfaction with the trip was higher at the Tapajós $(\mathrm{M}=5.04)$ compared to Anavilhanas (4.57). This result was also found when visitors evaluated individual items of their trip. Though, all quality domains were better evaluated by Tapajós visitors. The Tapajós has been somewhat successful at meeting visitor's expectations despite the lack of infrastructure and difficult access, Tapajós visitors might be looking for an authentic experience in the Amazon. In contrary, the first contact with the urban environment in Novo Airão might either disappoint those looking for authenticity or creates high expectations on the quality of services and facilities.

Perceived crowding was not an issue in the two conservation units, in fact most visitors reported a positive impact of seeing others; therefore the concept of functional density was found to be the most appropriate one. Few visitors reported negative impacts. Around one-fourth were neither negatively nor positively affected, and the majority reported that seeing others while recreating enhanced their enjoyment. Contrary to the image of isolation commonly associated to the Amazon, visitors might not be seeking complete isolation or solitude in the study areas. The lack of differences found between the two locations can indicate a pattern among recreationists visiting the Amazon. This pattern may or may not be associated with the way how visitors perceive the area in terms of fear and vulnerability (Boakye, 2012). Another assumption, supported in literature, has to do with the cultural factor, that the Brazilian culture would appreciate having more people around while recreating. Pierce (2011) emphasized that the notion of crowding can vary across countries, cultures, and settings. Therefore, there is a need for a crowding model applicable to multiple locations. Unquestionably, the US based crowding model made and still makes its contribution to the tourism and outdoor recreation field, especially on setting limits and numbers to preserve the environment and the visitor's experience (Pierce, 
2011). However, with all the changes happening in the contemporary world it may be relevant to investigate the recreational settings in which crowding may result in a positive outcome for the visitor and the destination.

\section{RQ2: Is there a relationship between crowding and visitors' satisfaction in the overall sample?}

This question was to understand the extent crowding/functional density is present in the Amazon's sample and its relation to the satisfaction level of the visitors. The results of this study reinforce what others researchers have found in the US (Manning, 2011). The variables crowding and satisfaction were found to not have a strong relationship in the overall sample. Although the results indicated that visitors in the Brazilian Amazon perceive crowding differently from visitors in the US, the data collected in Brazil contradicts Heberlein and Shelby's bivariate model based on the premise of increased use/decreased satisfaction. Thus the findings confirm that a bivariate satisfaction model cannot be used as strong indicator for satisfaction. A number of other variables should be taken into account when accessing satisfaction levels, otherwise results can be misinterpreted leading to poor management decisions. Manning et al (1999) discussed a multivariate crowding model recognizing a multitude of variables associated with satisfaction that might explain the lack of relationship between the variables of satisfaction and crowding. Manning (1999) postulated that "use level is not interpreted negatively as crowding until it is perceived to interfere or disrupt one's objectives or values" (p.100). Along with situational variables afore mentioned in this work, personal characteristics such as preference and expectations, and characteristic of other visitors regarding type, group size and behavior also can influence interpretations of crowding (Ditton, Fedler, \& Graefe, 1983).

Few US based studies found similar results to the ones presented in this research. Schuster and Dawson (2008) noted in their study that recreationists made use of coping 
mechanisms and other strategies to overcome a problem or frustration and achieve satisfaction. This is one of the possible explanations of why visitors, even though experiencing crowding, still report high satisfaction levels.

\section{RQ2.1: Do age, gender, and frequency of visit affect perceived crowding on overall sample?}

The demographic variables age, gender, and first time versus repeat visitors were found to not be significant predictors of perceived crowding/functional density. The choice of using these variables was based on Zehrer and Raich's (2016) model of crowding effects and customer satisfaction in which demographics and repeat visitors are hypothesized as influencing perceived crowding. Contrary to the results of Zehrer and Raich, the findings of this study demonstrated no impact of the variables under analysis on perceived crowding. This leads to the conclusion that in the two locations in the Amazon, demographic variables along with frequency of visit cannot be used as predictors for levels of crowding. Accordingly, it can be implied that in the Amazon case there is a combination of other variables influencing perceived crowding. The cultural component might play an important role in these results.

\section{Management Implications}

One of the aims of this study was to gather data to understand the current flow of visitors in the Amazon by zooming into their specific characteristics. Knowing that this type of information is crucial for managing public use and developing tourism in protected areas; this section focus only on the pieces of this study that pose practical implications for managers.

As mentioned in other studies and reinforced on this one, incorporating visitor monitoring programs into the management of the Tapajos National Forest and Anavilhanas National Park is crucial. This is useful a tool for assessment and evaluation of impacts. The methodology applied in this study for monitoring visitors is an example of how social data is 
collected and analyzed. The survey instrument can be modified according to the focus of the assessment. The use of technologies such as game cameras, trail and traffic counters have been proved to be useful to understand visitor behavior and habits (Gordon \& Muhar, 2003; Arnberger et al, 2005). This type of monitoring, although it seems expensive, presents a variety of uses and skips the process of hiring staff to collect data. Not only would the two areas in this study benefit, but other conservation units as well.

Implementing a methodology for monitoring public use in conservation units involves engagement of different parties, from federal agency, community, and stakeholders. Strengthening partnerships is fundamental for gaining assistance on data collection and analysis. It is worth mentioning that the efforts for monitoring visitor use is not valid until applied to management decisions. This study found a lack of information regarding visitation in conservation units in the Amazon region. Therefore, it is unknown as to what extent managers of this areas have been accessing science based information on the decision making process. This can directly affect the efficiency of regulations regarding public use. It is important to point out that these regulations set the roles for public use. Thus, management decisions have a direct effect on tourism development.

Designing marketing plans focused on visitor profiles, and aligned to the conservation unit's management plan, is also important for the growth of tourism in the Amazon. In both conservation units visitors were mostly from the areas near the park/forest. The existence of regional tourism is evident and can be solidified through actions promoting the area within the region. One way to do this is supporting special promotions targeting in-state visitors so they can become frequent visitors. These type of visitors are responsible for continuous support to the local economy (Tiefenbacher et al, 2000). 
In both locations, managers should ensure a safe environment for the practice of outdoor recreation activities in the areas, mainly at the ANP where safety and security was rated lower compared to the TNF. Also, when planning infrastructure managers should be mindful to the type of groups visiting the area and its specific needs.

Due to the existing demand for high educated visitors in both areas, the development of educational activities targeting this public is recommended. Additionally, interpretive signs could be incorporated as either complementary or main components of educational activities. Especially at ANP, informative signage including information such as limits of the park is recommended.

Since visitors primarily visit the Tapajos National Forest and the Anavilhanas National Park to experience nature and culture managers should emphasize and include specific activities to promote cultural tourism in the two conservation units. Also, access was found to be an important issue in these areas. Before doing so, investments on access, especially road maintenance, should be made.

For the Anavilhanas location, development of basic infrastructure to house recreational activities inside the Park is important. Currently tourism concentrates in only one area and the activity is viewing wildlife, specifically the pink dolphins. Families and couples are the most prevalent type of group visiting the park, activities and tourism packages targeting these groups would enhance the quality of their visit.

The Tapajós site has an advantage of already having some infrastructure due to the communities that live in the area. However, this infrastructure may need be supplemented to better attend to the needs of the visitors. Results of this study also shows that the sociocultural of the traditional communities could be explored as a component of tourism. The National Forest 
has a potential for ecotourism and this should be taken into account by the managers (Tanner et al, 1997). The community's perceptions about tourism is as important as visitor's perceptions about its experience. Collective involvement is crucial for short and long term results in tourism. The Tapajós National Forest should seek more benefits of the flow of tourists already visiting Alter do Chão while developing its own name as a destination.

\section{Recommendations for Future Research}

The present study was successful in answering the research questions proposed and the findings point towards more investigation. This section highlights a number of new opportunities that could be explored in future research.

There is a need for cross comparative studies on crowding in outdoor recreation. In that process it may be necessary to rethink the traditional crowding model based on a dominant US perspective. Additionally, adjustments to the measurement scale are needed in order to make it more sensitive to situations in which functional density may be the case. Furthermore, investigation on cultural influence and crowding using the variable country of origin could also be helpful in understanding these differences.

Specific to the Brazil case, expanding studies on crowding using/testing different approaches such as the use of digital photographs simulating the number of users in an area is also recommended. Visual research methods have been successfully applied on crowding studies in the US revealing more accurate results (Manning et al, 2009).

Furthermore, aligned with this work, other studies should be conducted in different conservations units to investigate whether or not functional density is a pattern among recreationists in Brazil. It is also important to explore what other variables could be influencing the results. For work within the Amazon region, factors such as safety, and to what extent the 
words associated with the image of the Amazon (inhospitable, dangerous) impact the visitor's perception of crowding could be studied.

In terms of data analysis, Vaske's Potential for Conflict Index (PCI2) analysis should be conducted. This type of analysis is key for interpreting bipolar data from the positive and negative scales. This analysis will allow the findings to be more applicable to managerial concerns.

\section{Conclusions}

This study aimed at understanding the profile of users of two conservation units in the Brazilian Amazon. Also embedded in this work was an exploration of the concept of crowding.

This thesis has shown that much effort is needed in terms of recreation research in protected areas in the Brazilian Amazon. The region has many natural attributes that can be of interest to a variety of visitors. However, visitation in the conservation units lack control and organization. Contrary to its neighboring countries, Brazil still struggles on using Amazon’s full potential to attract visitors to generate revenue (Ministério do Turismo, n.d; Neves, 2016). When well managed, visitation can expand the spectrum of opportunities for conservation (Boza, 1993). The financial outcome of having visitors in these areas can support local economy. In a long term, ideally, conservation units can contribute to national economy.

In terms of crowding, the findings of this work indicated that even though recreational use has been increasing in the two study areas, crowding does not appear to be an issue that should concern managers. However, over time comparative visitor monitoring studies are crucial for tracking changes in visitor profiles, interests, and perceptions as tourism activities intensify.

Lastly, it is essential to emphasize the importance of linking this research to US-based studies. Testing the applicability of methods in different contexts strengthens and nurture 
international cooperation in recreation studies. It also challenges researchers to rethink theories and models. The relationship of humans with nature is ever changing and the rise of new outdoor recreation trends is inevitable. Protected areas need to keep up with visitor's demands and make wise decisions for promoting conservation and enhancing the quality of the visits. Hopefully, the findings and concepts introduced in this research will inspire more researchers to investigate practical answers for the support of tourism in protected areas in the Amazon and around the world. 


\section{REFERENCES}

Allen, K., Evans, G. \& Lepore, S. (2000). Cross-cultural differences in tolerance for crowding: fact or fiction. Journal of Personality and Psychology, 79(2), 204-210.

Arngerger. A., Haider, W., \& Brandenburg, C. (2005). Evaluating visitor-monitoring techniques: A comparison of counting and video observation data. Environmental Management, 36:2, 317327.

Babin, B.J., Darden, W. \& Griffin, M. (1994). Work and/fun: Measuring hedonic and utilitarian shopping value. Journal of Consumer Research, 22, 644-656.

Berg, B. L. H. (2004). Qualitative research methods for the social sciences (Vol.5). Boston, MA: Pearson.

Birth of a National Park. (n.d.). Retrieved from

https://www.nps.gov/yell/learn/historyculture/yellowstoneestablishment.htm

Boakye, K. A. (2012). Tourists' views on safety and vulnerability. A study of some selected towns in Ghana. Tourism Management, 33, 327-333.

Boza, M. (1993). Conservation in Action: Past, Present, and Future of the National Park System of Costa Rica. Conservation Biology, 7:2, 239-247.

Burns, R.C., \& Moreira. J. C. (2013). Visitor management in Brazil's protected areas: Benchmarking for best practice in resource management. The George Wright Forum, 30, 163-170.

Burns, R.C., \& Moreira. J. C. (2013). Visitor monitoring in the Tapajós National Forest, Brazil. In Visitor Management in Tourism Destination (pp. 91-101). New Zealand: Dunedin.

Burns, R.C., \& Moreira, J.C. (2015). 2013 Brazil Visitor Use Monitoring (interim report), 157 pages.

Cervinka, R., Höltge, J., Pirgie, L., Schwab, M., Sudkamp, J., Haluza, D., Arnberger, A., Eder, R., \& Ebenberger, M. (2014). Green Public Health - Benefits of Woodlands on Human Health and Well-being [Zur Gesundheitswirkung von Waldlandschaften]. Vienna, Austria: Bundesforschungszentrum für Wald (BFW).

Ditton, R. B., Fedler, A. J., \& Graefe, A. R. (1983). Factors contributing to perceptions of recreational crowding. Leisure Sciences, 5(4): 273-287. 
Driver, B. \& Toucher, R. (1970). Toward a behavioral interpretation of recreational engagements, with implications for planning. Elements of Outdoor Recreation Planning. Ann Arbor, MI: University Microfilms, 9-31.

Dupeyras, A. and MacCallum (2013). Indicators for measuring competitiveness in tourism: A guidance document. OECD Tourism Papers, 3 - 65.

E Souza, A. D. (2014, December 19). Repensando a Cooperação Internacional para o Desenvolvimento. Retrieved from http://www.ipea.gov.br/portal/index.php?option=com_content\&view=article\&id=24257

English, D. B. K., Kocis, S. M., Zarnoch, S. J., \& Arnold, J. R. (2002). Forest Service National Visitor Use Monitoring Process: Research Method Documentation. Gen. Tech. Rep. SRS-57. Asheville, NC: U.S.

Eroglu, S. A. \&, Machleit, K. A. (1990). An empirical investigation of antecedents and consequences of retail crowding. Journal of Retailing (Summer), 66, 201-221.

Eroglu, S. A., Harrell, G. D. (1986). Retail crowding: theoretical and strategic implications.

Florestas do Brasil em resumo - 2013: dados de 2007-2012. / Serviço Florestal Brasileiro. Brasília: SFB, 2013.

Freedman, J. L, Lavy, A. S., Buchanan, R.W. \& Price, J. (1972). Crowding and human aggressiveness. Journal of Experimental Social Psychology, 8, 528-548.

Fundação Instituto de Pesquisas Econômicas (2012). Caracterização e dimensionamento do turismo doméstico no Brasil - 2010/2011, Relatório Executivo.

Garcia, L. V. M. (2015). Cachoeira da Mariquinha: Impactos e potencialidades do uso público no Parque Nacional dos Campos Gerais - PR. Dissertação de mestrado.

Gordon, C. \& Muhar, A. (2003). Monitoring options for visitor numbers in national parks and national areas. Journal for Nature Conservation, 11, 240-250.

Graefe, A. R., Vaske, J. J., \& Kuss, F. R. (1984). Social carrying capacity: An intefration and synthesis of twenty years of research. Leisure Sciences, 6, 395-431.

Hall, E. T. (1966). The Hidden Dimension, Doubleday: New York.

Heberlein, T. A., \& Kuentzel, W. F. (2002). Too many hunters or not enough deer? Human and biological determinants of hunter satisfaction and quality. Human Dimensions of Wildlife, 7(4), 229-250.

Heberlein, T. A., Trent, J. P., \& Baumgartner, R. M. (1982). The influence of hunter density on 
firearm deer hunters' satisfaction. Transactions of the 47th North American Wildlife and Natural Resources Conference, 47, 665-676.

Heberlein, T. A., \& Vaske, J. J. (1977). Crowding and visitor conflict on the Bois Brule River. University of Wisconsin. Water Resources Center Technical Report OWRT A-066-WAS, Madison.

Health Council of the Netherlands (2004). Nature and Health: The influence of nature on social, psychological and physical wellbeing. http://www.gezondheidsraad.nl/sites/default/files/Nature\%20and\%20health.pdf

Hui, M. K., Bateson, J. E. (1991). Perceived control and the effects of crowding and consumer choice on the service experience. Journal of Consumer Research, 18, 174-84. Journal of Retailing, 62, 347-363.

ICMBio (2016). Aumenta número de visitante em Unidade de Conservação. Retrieved from http://www.icmbio.gov.br/portal/ultimas-noticias/4-destaques/7579-numero-devisitantes-nas-ucs-federais-aumenta-320

Iwata, O. (1992). Crowding and behaviorin Japanese public spaces: Some observations and speculations, Social Behavior and Personality, 20(1):57-66.

WVU Recreation Research LAB (2015). Campos Gerais Internal Report.

WVU Recreation Research LAB (2016). Jericoacoara Internal Report.

Kainzinger, S., Burns, R. C., \& Arnberger, A. (2015). Whitewater boater and angler conflict, crowding and satisfaction on the North Umpqua River, Oregon. Human Dimensions of Wildlife, 20(6), 542-552.

Kinker, S. (2002). Ecoturismo e conservação da natureza em parques nacionais. São Paulo: Papirus.

Larry M. Gigliotti \& Chase L. (2014) A Bivalent Scale for Measuring Crowding Among Deer Hunters, Human Dimensions of Wildlife: An International Journal, 19(1), 96-103, DOI: 10.1080/10871209.2013.811619

Likert, R. (1932). A technique for the measurement of attitudes. Archives of psychology. 22(140), 5-55.

Mammadov, R. (2012). The importance of transportation in tourism sector. $7^{\text {th }}$ Silk Road International Conference, $381-386$. 
Manning, E. R. \& Valliere, A. W. (2001). Coping in outdoor recreation: causes and consequences of crowding and conflict among community residents, Journal of Leisure Research, 33(4), 410-426.

Manning, E. R. (2007). Parks and carrying capacity: Commons without Tragedy. Washington DC: Island Press.

Manning, E. R., Valliere, A.W., Wang, B., \& Jacobi, C. (1999). Crowding norms, alternative measurement approaches. Leisure Sciences, 21(1), 97-115.

Manning, R. (2011). Studies in Outdoor Recreation: Search and Research for Satisfaction (3rd Edition). Corvallis, OR: Oregon State University Press.

Manning, E. R., \& Lime, D. (1996). Crowding and carrying capacity in the National Park System: Toward a social science research agenda. Crowding and Congestion in the National Park System: Guidelines for Management and Research. St. Paul: University of Minnesota Agriculture Experiment Station Publication, 86, 27-65.

Manning, Robert. (n.d). Crowding and carrying capacity in outdoor recreation: from normative standards to standards of quality. Retrieved from https://www.uvm.edu/parkstudieslaboratory/publications/Crowding_and_Carrying_Capa city.pdf

Marion, J. L., \& Farrell, T. A (2002). Management practices that concentrate visitor activities: camping impact management at Isle Royale National ParK, USA. Journal of Environmental Management, 66, 201-2012.

Mario, J. L. \& Reid, S. E. (2007). Minimising visitor impacts to protected areas: The efficacy of low impact education programmes. Journal of Sustainable Tourism, 15:1, 5-27.

Medeiros, R. (2006). Evolução das tipologias e categorias de áreas protegidas no Brasil. Ambiente \& Sociedade, 9, 41-63.

Medeiros, R. \& Young, C. E. F. (2011). Contribuição das unidades de conservação brasileiras para a economia nacional: Relatório Final. Brasília: UNEP/WCMC. 120p.

Ministério do Turismo (2016). Anuário Estatístico de Turismo - 2016.

Ministério do Turismo (n.d). Estudos da Competitividade do Turismo Brasileiro. Retrieved from http://www.turismo.gov.br/sites/default/turismo/o_ministerio/publicacoes/downloads_pu blicacoes/ANxLISE_DE_ALGUNS_DESTINOS_COMPETITIVOS_DO_BRASIL_EM _TERMOS_DE_TURISMO_INTERNACIONAL.pdf

Ministério do Turismo (2016). Pesquisa com visitantes domésticos e internacionais dos jogos Rio 2016 - Resultados preliminares. 
Monz, A. C., Cole, D. N., Leung, Y., and Marion, J.L. (2009). Sustaining visitor use in protected areas: Future research opportunities in recreation ecology based on USA experience. Retrieved from https://link.springer.com/article/10.1007/s00267-009-9406-5

Moss, S. (2016). Psychological reactance theory. Retrieved from http://www.sicotests.com/psyarticle.asp?id=65.

Moyle, B. D. \& Croy, W. G. (2007). Crowding and visitor satisfaction during the off-season: Port Campbell National Park, Annals of Leisure Research, 10(3/4), 518-531.

O Sistema Nacional de Unidades de Conservação da Natureza. (2010). Retrieved from http://www.mma.gov.br/estruturas/240/_publicacao/240_publicacao05072011052536.pdf

Neves, B (2016). Por que ninguém viaja para o Brasil? Retrieved from http://super.abril.com.br/sociedade/por-que-ninguem-viaja-para-o-brasil/

Pádua, M. T. J. (1978).Categorias de Unidades de Conservação - Objetivos de Manejo. Boletim $F B C N, 13,78-84$.

Palhares, L. G. (2003). The role of transport in tourism development: Nodal functions and management practices. International Journal of Tourism Research (5), 403-407.

Pierce, Philip L. Tourist behavior and the contemporary world. Aspects of Tourism, 51.

Pimentel, D. S. \& Magro, T. C. (2011). Múltiplos olhares, muitas imagens o manejo de parques com base na complexidade social. GEOgrafia $(U F F)$, 92-113.

Plano de Manejo - Anavilhanas. (n.d.). Retrieved from http://www.icmbio.gov.br/parnaanavilhanas/anexos/13-plano-de-manejo.html

Pons, F., Laroche, M. \& Mourali, M. (2006). Consumer reactions to crowded retail settings: Cross-cultural differences between North America and the Middle East. Journal of Marketing Research, 23(3): 555-572.

Prideaux, B. \& Cooper, C. (2003). Marketing and destination growth: A symbiotic relationship or simple coincidence? Journal of Vacation Marketing, 9:1, 35-51.

Rapoport, A. (1980). Environmental preference, habitat selection and urban housing. Journal of Social Issues, 36(3) 118-135.

Rodrigues de Jesus, V. (2010). Developing sustainable tourism in the Amazon rainforest of Brazil - premises, actions, challenges. Worldwide Hospitality and Tourism Themes, 2, 144-152. doi:10.1108/17554211011037831 
Romagnoli, F. C. (2009). Interpretação ambiental e envolvimento comunitário: ecoturismo como ferramenta para a preservação do boto-vermelho, Inia geoffrensis. Masters Thesis, Instituto Nacional de Pesquisas da Amazônia, Manaus, Brasil.

Sayan. S., Krymkowski, D. H., Manning. R.E., Valliere, W.A. \& Rovestald, E.L. (2013). Cultural influence on crowding norms in outdoor recreation: A comparative analysis of visitors to National Parks in Turkey and United States. Environmental Management, 52, 493-592.

Saayman, M. \& Saayman, A. (2006). Estimating the economic contribution of visitor spending in the Kruger National Park to the regional economy. Journal of Sustainable Tourism, 14:1, 67-81.

Schenini, P. C., Costa, A. M. \& Casarin, V. W. (2004). Unidades de Conservação: Aspectos históricos e sua evolução. Retrieved from http://www.ambiente.sp.gov.br/wpcontent/uploads/cea/PedroCarlosS.pdf

Schuster, M. R. \& Dawson, P. C (2008). An exploratory analysis of coping schemes used by paddlers who camped in the St. Regis Canoe area, New York. Proceedings of the 2008 Northeastern Recreation Research Symposium, 139-146.

Shelby, B., \& Heberlein, T. A. (1984). A conceptual framework for carrying capacity determination. Leisure Sciences, 6, 433-451.

Schmidt, D. E., \& Keating, J. P. (1979). Human crowding and personal control: An integration of the research. Psychological Bulletin, 86, 680-700.

Simões Neto, S. (2014, October 09). Plano de Manejo do Parque Nacional de Anavilhanas é revisado. Retrieved IIfrom http://www.idesam.org.br/plano-de-manejo-do-parquenacional-de-anavilhanas-e-revisado/\#.V-RLCPkrLRZ

Sonnenfeld, J. (1966). Variable values in space and landscape: An inquiry into the nature of environmental necessity. Journal of Social Issues, 12(4), 71-82.

Souza, T. B.(2016). Recreation classification, tourism demand and economic impacts analyses of the federal protected areas in Brazil. Doctoral dissertation. University of Florida, Florida, Gainesville.

SNUC - SISTEMA NACIONAL DE UNIDADES DE CONSERVAÇÃO LEI No 9.985. (2000). Retrieved September from http://www.mma.gov.br/estruturas/sbf_corredores/_arquivos/snuc.pdf

Stolkos, D. \& Altman, I. (Eds.) (1987). Handbook of environmental psychology. (Vol 1 \& 2). New York: Wiley.

Stolkos, D. (1972). On the distinction between density and crowding: some implication for future research. Psychological review, 79, 275-278. 
Sutherland. (1196). The International Dictionary of Psychology. New York: Crossword.

Tanner, Jullie B., Thomas, P., Sills, Erin O., \& Silva, S.S (1997). The potential demand for ecotourism in the Tapajós National Forest, Pará, Brazil. Retrieved from https://www.srs.fs.usda.gov/econ/pubs/fpei/fpei62.pdf

Tiefenbacher, J. P., Day, F. A., and Walton, J. A. (2000). Attributes of repeat visitors to small tourist-oriented communities. The Social Science Journal, 37:2, 299-308.

Vaske, J. J., Donnelly, M. P., \& Heberlein, T. A. (1980). Perceptions of crowding and resource quality by early and more recent visitors. Leisure Sciences, 3(4), 367-381.

Vaske, J. J., Maureen, D. P. \& James, P. P. (1996). Country of origin, encounter norms, and crowding in a frontcountry setting. Leisure Sciences, 18, 161-176.

Vaske, J.J., Shelby, B. (2008). Crowding as a descriptive indicator and evaluative standard: results from 30 years of research. Taylor \& Francis Group, 30, $111-126$.

Veríssimo, A., Rolla, A., Ribeiro, M. B., \& Salomão, R. (n.d.). Áreas Protegidas na Amazônia Brasileira: Avanços e desafios. Retrieved from http://imazon.org.br/areas-protegidas-naamazonia-brasileira-avancos-e-desafios-2/

Viveiros de Castro, E., Souza. T. B., \& Thapa, B. (2015). Determinants of tourism attractiveness in the National Parks of Brazil. Parks, 21(2), 51-62.

Wagar, J. A. (1964). The Carrying capacity of wild lands for recreation. Forest Science Monograph 7. Washington, DC: Society of American Foresters.

Westlake, J. and D. Robbins (2005). "Transportation" in Cooper C., Fletcher., Fyall, A., Gilbert, D. and S. Wanhill. Tourism: Principles and Practice, $3^{\text {rd }}$ edition, Pearson Education Limited, Essex.

White, R. (1985). American Environmental History: The Development of a New Historical Field. Retrieved from http://www.jstor.org/stable/3639634?seq=1\&cid=pdf-reference\#fndtnreferences_tab_contents

Whiting, A. \& Nakos, G. (2000). Functional Density and its impact on retail satisfaction in crosscultural contexts: Can crowded stores be a good thing for retailers? International Business: Research Teaching and Practice, 2 (1-11).

Why we work internationally. (n.d.). Retrieved from http://www.fs.fed.us/aboutagency/international-programs/why-we-work-internationally

Williams, F. (2016, January). The Power of Parks. National Geographic, 229(1), 54-67. 
Zehrer, A. \& Raich, F. (2016). The impact of perceived crowding on customer satisfaction. Journal of Hospitality and Tourism Management, 29, 88-98, DOI: 10.1016/j.jhtm.2016.06.007. 


\section{APPENDIX A}

\section{SURVEY INSTRUMENT}

\section{ICMBio \\ Research on Forest/National Park Use and Recreation}

\section{Choose your location}

$\underline{100 \%}$ Overall sample

2. What is your country of residence? $\underline{83.5 \%}$ Brazil $\underline{16.5 \%}$ Other [Please specify] Open

3. [If Brazil] State:

$\leq 1.0 \%$ Acre

$\leq 1.0 \%$ Alagoas

$\leq 1.0 \%$ Amapá

$\underline{27.6 \%}$ Amazonas

$\leq 1.0 \%$ Bahia

$\underline{1.2 \%}$ Ceará

$\underline{3.7 \%}$ Distrito Federal

$\leq 1.0 \%$ Espírito Santo

$<1.0 \%$ Goiás $\leq 1.0 \%$ Maranhão

$\leq 1.0 \%$ Mato Grosso

$\leq 1.0 \%$ Mato Grosso do Sul

$\underline{3.1 \%}$ Minas Gerais

$\underline{22.3 \%}$ Pará

--- Paraíba

$2.5 \%$ Paraná

$\leq 1.0 \%$ Pernambuco

$\leq 1.0 \%$ Piauí

$\leq 1.0 \%$ Goiânia

$\underline{4.8 \%}$ Manaus

$\leq 1.0 \%$ Novo Airão

--- Ponta Grossa

$\leq 1.0 \%$ Porto Alegre

$\leq 1.0 \%$ Recife $\underline{8.3 \%}$ Rio de Janeiro

--- Rio Grande do Norte

$\leq 1.0 \%$ Rio Grande do Sul

$\leq 1.0 \%$ Rondônia

$\leq 1.0 \%$ Roraima

$\leq 1.0 \%$ Santa Catarina

$\underline{25.0 \%}$ São Paulo

--- Sergipe

--- Tocantins

4. [If Brazil] City:

$\underline{5.4 \%}$ Belém

$2.9 \%$ Belo Horizonte

4.3\% Brasília

$\leq 1.0 \%$ Cuiabá

$1.9 \%$ Curitiba

$\leq 1.0 \%$ Fortaleza

5. What is your age? Mean $=37.26$

6. What is your gender? $48.4 \%$ Male _51.6\%_Female

7. What is your education level? Please select one option:

$\leq 1.0 \%$ Elementary _ $7.6 \%$ _High School_ 24.3\%_Some College $\underline{35.8 \%}$

College Graduate $\quad \underline{31.3 \%}$ Post Graduate

8. How far in advance did you plan your trip to the Forest/National Park? Please select one option:

$\frac{17.7 \%}{17.0 \%}$ today days $-\frac{30.0 \%}{1 \text { month }} 2-3$ days $\frac{9.5 \%}{13.6 \%}$ 4-7 days $1-3$ months $\_.3 \%$ more than 3 months

9. Is this your first visit to this National Forest/National Park? $85.6 \%$ Yes $\quad 14.4 \%$ No 
10. [If no] Year in which you made your first visit to this Forest/National Park (Ex: 2004): Mean $=2010.93$

11. [If no] In a typical year, how many days do you come to this National Forest/National Park? Mean $=4.28$

12. Is your trip today... $29.3 \%$ an overnight visit to this area $\underline{70.7 \%}$ a day trip

13. [If overnight] How long is your visit? Mean=2.91 days

14. [If a day trip] How long is your visit? Mean=6.19 hours

15. What transportation mode(s) did you use to arrive at this site today? 3.4\%_Taxi_25.9\%_Private car_ 12.6\%_Rental car_3.5\% Motorcycle _11.1\%_Public Bus $5.1 \%$ Private Bus _ $<1.0 \%$ Bicycle _-- Train $\leq 1.0 \%$ On foot $11.1 \%$ Boat $25.3 \%$ Speedboat _1.2\%_Airplane (only if arriving at this specific site by airplane) 1.0 Other [Please specify]_open_

16. How many adults are in your group today? _Mean $=5.79$

17. How many children under 16 years of age are in your group today? _Mean=2.61

18. Which of the following best describes the composition of your group? Please select an option:

$\underline{8.7 \%}$ Alone $\underline{12.7 \%}$ Couple $\underline{19.9 \%}$ Family $29.5 \%$ Friends $\_17.5 \%$ Family and Friends 6.2\% Commercial Group (group of people who paid a fee to participate in this trip)

$1.3 \%$ Organized Group (club or other organization)

$4.4 \%$ Education

$\leq 1.0 \%$ Other [Please specify]_open

19. What activities have you participated in during this visit?

_68.5\%_Hiking _65.2\%_Swimming _6.8\% _ Barbeque _62.6\% Lunch/Picnic 3.7\% Viewing Waterfalls

$\underline{46.9 \%}$ Boating / Canoeing $\underline{29.0 \%}$ Viewing Wildlife $\underline{2.0 \%}$ Snorkeling / Diving $\leq 1.0 \%$ Kite Surfing

---Exploring dunes with a motor vehicle $\leq 1.0 \%$ Rafting $\leq 1.0 \%$ Gliding $\leq 1.0 \%$ Canyoneering

---Mountain Climbing / Climbing --- Visiting the caves

Camping

$\underline{44.0 \%}$ Buying Crafts $\underline{39.7 \%}$ Community Area $\underline{10.3 \%}$ Get to know a famous tourist attraction

$\underline{1.9 \%}$ Other [Please specify]_open_

20. Which one of those is your primary activity for this recreation visit? Please select one option: 
38.0\%_Hiking _12.2\% Swimming _ $<1.0 \%$ Barbeque _2.3\% Lunch/Picnic --- Viewing Waterfalls $\underline{3.9 \%}$ Boating / Canoeing $\underline{17.9 \%}$ Viewing Wildlife $\leq 1.0 \%$ Snorkeling /

Diving $\leq 1.0 \%$ Kite Surfing --- Exploring dunes with a motor vehicle --- Rafting --- Gliding --- Canyoneering --- Mountain Climbing / Climbing --- Visiting the caves ---Use of riding animals $2.6 \%$ Camping $\leq 1.0 \%$ Buying Crafts $\underline{4.6 \%}$ Community Area $\underline{6.0 \%}$ Get to know a famous tourist attraction $\underline{10.3 \%}$ Other [Please specify]_open_

21. Of the following, what was the main reason for your visit? Please select an option:

$\underline{8.8 \%}$ I came because I like the place itself

6.4\% I came because it's a good place to do the outdoor activities that I like

9.5\% I came because I want to spend more time with my friends/family

$\underline{2.7 \%}$ I came because it is close to home

$\underline{48.6 \%}$ I came because I enjoy nature

$\underline{23.9 \%}$ I came because it's a good place to experience the culture of this area

22. Overall, how would you rate your visit to this area today? Mean $=\underline{5.04}$

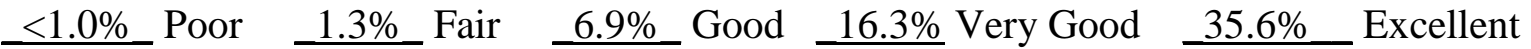
$39.5 \%$ Perfect

23. In general, how would you rate the quality of each item on a scale from 1 to 5 , with 1 meaning poor and 5 meaning excellent?

\begin{tabular}{|l|c|c|c|c|c|c|c|}
\hline & Poor & Fair & Good & $\begin{array}{c}\text { Very } \\
\text { Good }\end{array}$ & Excellent & $\begin{array}{c}\text { Not } \\
\text { Applicable }\end{array}$ & Mean \\
\hline Cleanliness of area & $<1.0 \%$ & $4.8 \%$ & $31.2 \%$ & $27.9 \%$ & $34.1 \%$ & $1.2 \%$ & 3.91 \\
\hline Safety and Security & $<1.0 \%$ & $2.4 \%$ & $19.1 \%$ & $37.3 \%$ & $40.2 \%$ & $<1.0 \%$ & 4.16 \\
\hline Trail Condition & $<1.0 \%$ & $1.5 \%$ & $13.1 \%$ & $23.9 \%$ & $33.7 \%$ & $27.6 \%$ & 4.23 \\
\hline Facilities & $<1.0 \%$ & $3.8 \%$ & $23.7 \%$ & $35.1 \%$ & $29.3 \%$ & $7.7 \%$ & 3.96 \\
\hline Access Roads & $2.3 \%$ & $10.6 \%$ & $31.9 \%$ & $36.2 \%$ & $16.3 \%$ & $2.8 \%$ & 3.55 \\
\hline $\begin{array}{l}\text { Environmental } \\
\text { Interpretation } \\
\text { (panels, guides, } \\
\text { brochures, etc.) }\end{array}$ & $8.3 \%$ & $15.3 \%$ & $25.2 \%$ & $21.3 \%$ & $23.2 \%$ & $6.8 \%$ & 3.63 \\
\hline
\end{tabular}

24. How did the number of people you saw today affect the overall enjoyment of your trip?
$5.3 \%$
$<1.0 \% \quad 1.2 \%$
$1.3 \%$
$19.4 \%$
$5.4 \%$
$8.8 \%$
$24.2 \%$

$34.1 \%$

\begin{tabular}{lllllllll}
-4 & -3 & -2 & -1 & 0 & 1 & 2 & 3 & 4 \\
\hline Reduced my enjoyment & \multicolumn{1}{c}{ No Effect } & & $\begin{array}{c}\text { Enhanced my } \\
\text { enjoyment }\end{array}$
\end{tabular}




\section{ICMBio \\ Research on Forest/National Park Use and Recreation}

1. Choose your location

$\underline{100 \%}$ FLONA Tapajós

2. What is your country of residence? $\underline{84.3 \%}$ Brazil $\underline{15.7 \%}$ Other [Please specify] Open

3. [If Brazil] State:

\begin{tabular}{|c|c|c|}
\hline$\leq 1.0 \%$ Acre & $\leq 1.0 \%$ Maranhão & $\underline{8.4 \%}$ Rio de Janeiro \\
\hline$\overline{<1.0 \%}$ Alagoas & $\overline{\leq 1.0 \%}$ Mato Grosso & --- Rio Grande do Norte \\
\hline$\overline{<1.0 \%}$ Amapá & $\overline{\leq 1.0 \%}$ Mato Grosso do Sul & 1.6\% Rio Grande do Sul \\
\hline 4.8\% Amazonas & $\underline{3.6 \%}$ Minas Gerais & $\overline{\leq 1.0 \%}$ Rondônia \\
\hline$\leq 1.0 \%$ Bahia & $\underline{43.5 \%}$ Pará & $\leq 1.0 \%$ Roraima \\
\hline$\leq 1.0 \%$ Ceará & $\leq 1.0 \%$ Paraíba & $\leq 1.0 \%$ Santa Catarina \\
\hline 4.4\% Distrito Federal & 2.3\% Paraná & $\underline{22.1 \%}$ São Paulo \\
\hline$\overline{<1.0 \%}$ Espírito Santo & $\leq 1.0 \%$ Pernambuco & --- Sergipe \\
\hline$\overline{<1.0 \%}$ Goiás & $\overline{\leq 1.0 \%}$ Piauí & --- Tocantins \\
\hline \multicolumn{3}{|l|}{ 4. [If Brazil] City: } \\
\hline$\underline{5.4 \%}$ Belém & $\leq 1.0 \%$ Goiânia & 7.6\% Rio de Janeiro \\
\hline $2.9 \%$ Belo Horizonte & $\overline{4.8 \%}$ Manaus & $\leq 1.0 \%$ Salvador \\
\hline$\underline{4.3 \%}$ Brasília & $\leq 1.0 \%$ Novo Airão & $\underline{30.6 \%}$ Santarém \\
\hline$\leq 1.0 \%$ Cuiabá & --- Ponta Grossa & $\underline{20.6 \%}$ São Paulo \\
\hline$\overline{1.9 \%}$ Curitiba & $\leq 1.0 \%$ Porto Alegre & $\overline{19.4 \%}$ Other (Please specify): \\
\hline$\leq 1.0 \%$ Fortaleza & $\leq 1.0 \%$ Recife & $\underline{\text { Open }}$ \\
\hline
\end{tabular}

5. What is your age? _Mean $=38.54$

6. What is your gender? $46.7 \%$ Male _53.3\%_Female

7. What is your education level? Please select one option:

$1.5 \%$ Elementary _14.3\% High School _18.3\%_Some College $\underline{35.5 \%}$ _ College Graduate $\quad \underline{30.4 \%}$ Post Graduate

8. How far in advance did you plan your trip to the Forest/National Park? Please select one option:

\begin{tabular}{ll}
$-15.8 \%$ \\
\hline $13.0 \%$ \\
\hline
\end{tabular}

9. Is this your first visit to this National Forest/National Park? _84.6\%_Yes _ $15.4 \%$ No 10. [If no] Year in which you made your first visit to this Forest/National Park (Ex: 2004): Mean $=2009.68$

11. [If no] In a typical year, how many days do you come to this National Forest/National Park? $\underline{\text { Mean }=3.68}$

12. Is your trip today... $\underline{46.3 \%}$ an overnight visit to this area $\underline{53.7 \%}$ a day trip 
13. [If overnight] How long is your visit? Mean=4.09 days

14. [If a day trip] How long is your visit? Mean= 5.55 hours

15. What transportation mode(s) did you use to arrive at this site today?

3.9\%_Taxi_42.9\%_Private car 9.9\%_Rental car_2.4\% Motorcycle 7.5\%_ Public Bus 4.3\%_Private Bus _ $<1.0 \%$ Bicycle --- Train $1.7 \%$ On foot $\_12.4 \%$ Boat $14.3 \%$ Speedboat $1.5 \%$ Airplane (only if arriving at this specific site by airplane) $\leq 1.0$ Other [Please specify]_open_

16. How many adults are in your group today? _Mean $=4.93$

17. How many children under 16 years of age are in your group today? _Mean=2.25

18. Which of the following best describes the composition of your group? Please select an option:

$\underline{6.9 \%}$ Alone $\underline{19.1 \%}$ Couple $\underline{28.9 \%}$ Family $\underline{22.3 \%}$ Friends _ $13.5 \%$ Family and Friends

4.9\% Commercial Group (group of people who paid a fee to participate in this trip)

$\underline{2.1 \%}$ Organized Group (club or other organization)

$2.6 \%$ Education

$\leq 1.0 \%$ Other [Please specify]_open_

19. What activities have you participated in during this visit?

49.7\%_Hiking _57.9\%_Swimming _7.3\%_Barbeque _50.3\%_ Lunch/Picnic 5.8\%

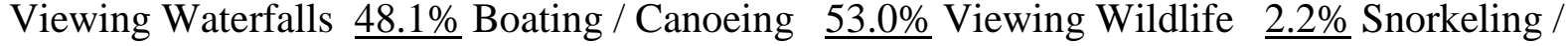
Diving $\leq 1.0 \%$ Kite Surfing --- Exploring dunes with a motor vehicle $\leq 1.0 \%$ Rafting $\leq 1.0 \%$ Gliding $1.3 \%$ Canyoneering --- Mountain Climbing / Climbing --- Visiting the caves --- Use of riding animals $\underline{4.8 \%}$ Camping $\underline{31.3 \%}$ Buying Crafts $\underline{29.6 \%}$ Community Area $\underline{10.9 \%}$ Get to know a famous tourist attraction $\underline{2.6 \%}$ Other [Please specify]_open_

20. Which one of those is your primary activity for this recreation visit? Please select one option:

24.4\%_Hiking 10.5\% Swimming__ $<1.0 \%$ Barbeque _2.0\%_ Lunch/Picnic $2.6 \%$ Viewing Waterfalls $5.9 \%$ Boating / Canoeing $29.7 \%$ Viewing Wildlife $\leq 1.0 \%$ Snorkeling / Diving $\leq 1.0 \%$ Kite Surfing --- Exploring dunes with a motor vehicle --- Rafting --- Gliding --- Canyoneering --- Mountain Climbing / Climbing --- Visiting the caves ---Use of riding animals $\underline{1.4 \%}$ Camping $\leq 1.0 \%$ Buying Crafts $\underline{2.8 \%}$ Community Area $\underline{8.4 \%}$ Get to know a famous tourist attraction $\underline{10.0 \%}$ Other [Please specify]_open_

21. Of the following, what was the main reason for your visit? Please select an option:

9.4\% I came because I like the place itself

5.7\% I came because it's a good place to do the outdoor activities that I like

$\underline{10.1 \%}$ I came because I want to spend more time with my friends/family

$\underline{1.7 \%}$ I came because it is close to home

$48.4 \%$ I came because I enjoy nature

24.7\% I came because it's a good place to experience the culture of this area 
22. Overall, how would you rate your visit to this area today? Mean $=\underline{4.80}$

$\underline{1.3 \%}$ Poor 5.9\% Fair 33.8\% Good 20.1\% Very Good 35.2\% Excellent $31.5 \%$ Perfect

23. In general, how would you rate the quality of each item on a scale from 1 to 5 , with 1 meaning poor and 5 meaning excellent?

\begin{tabular}{|l|c|c|c|c|c|c|c|}
\hline & Poor & Fair & Good & $\begin{array}{c}\text { Very } \\
\text { Good }\end{array}$ & Excellent & $\begin{array}{c}\text { Not } \\
\text { Applicable }\end{array}$ & Mean \\
\hline Cleanliness of area & $<1.0 \%$ & $5.9 \%$ & $33.8 \%$ & $26.7 \%$ & $31.7 \%$ & $1.0 \%$ & 3.83 \\
\hline Safety and Security & $<1.0 \%$ & $3.1 \%$ & $26.0 \%$ & $32.1 \%$ & $37.1 \%$ & $1.4 \%$ & 4.04 \\
\hline Trail Condition & $<1.0 \%$ & $1.6 \%$ & $13.5 \%$ & $20.6 \%$ & $27.3 \%$ & $36.8 \%$ & 4.16 \\
\hline Facilities & $<1.0 \%$ & $5.8 \%$ & $27.5 \%$ & $28.5 \%$ & $26.9 \%$ & $10.4 \%$ & 3.83 \\
\hline Access Roads & $7.6 \%$ & $12.6 \%$ & $30.8 \%$ & $28.7 \%$ & $17.1 \%$ & $3.2 \%$ & 3.36 \\
\hline $\begin{array}{l}\text { Environmental } \\
\text { Interpretation } \\
\text { (panels, guides, } \\
\text { brochures, etc.) }\end{array}$ & $6.5 \%$ & $11.0 \%$ & $28.6 \%$ & $25.0 \%$ & $23.6 \%$ & $5.2 \%$ & 3.51 \\
\hline
\end{tabular}

24. How did the number of people you saw today affect the overall enjoyment of your trip?

$\begin{array}{llllllll}3.9 \% & <1.0 \% & 1.2 \% & 1.1 \% & 22.6 \% & 5.4 \% & 10.5 \% & 20.7 \% \\ 34.3 \% & & & & & \end{array}$

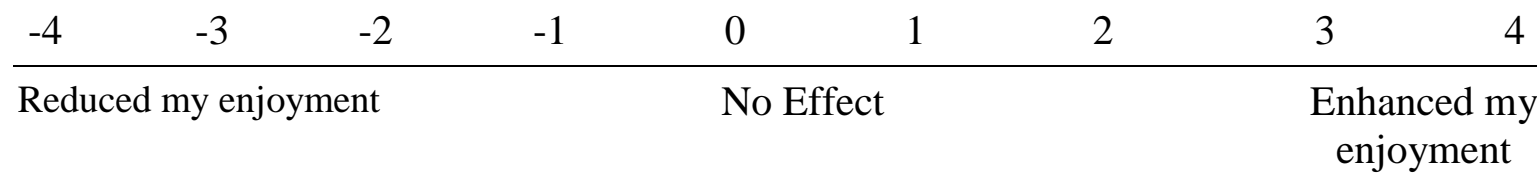




\section{ICMBio \\ Research on Forest/National Park Use and Recreation}

1. Choose your location:

$\underline{100 \%}$ Anavilhanas

2. What is your country of residence? $\underline{82.6 \%}$ Brazil $\underline{17.4 \%}$ Other [Please specify] Open

3. [If Brazil] State:

\begin{tabular}{|c|c|c|}
\hline$\leq 1.0 \%$ Acre & $\leq 1.0 \%$ Maranhão & $\underline{8.5 \%}$ Rio de Janeiro \\
\hline$\leq 1.0 \%$ Alagoas & $\leq 1.0 \%$ Mato Grosso & $\leq 1.0 \%$ Rio Grande do Norte \\
\hline$\leq 1.0 \%$ Amapá & $\leq 1.0 \%$ Mato Grosso do Sul & $\underline{2.2 \%}$ Rio Grande do Sul \\
\hline$\underline{50.6 \%}$ Amazonas & $\underline{2.7 \%}$ Minas Gerais & $\leq 1.0 \%$ Rondônia \\
\hline$\leq 1.0 \%$ Bahia & $\leq 1.0 \%$ Pará & $\overline{\leq 1.0 \%}$ Roraima \\
\hline$\underline{1.5 \%}$ Ceará & $\leq 1.0 \%$ Paraíba & $\leq 1.0 \%$ Santa Catarina \\
\hline$\underline{3.0 \%}$ Distrito Federal & $\leq 1.0 \%$ Paraná & $\underline{19.2 \%}$ São Paulo \\
\hline$\leq 1.0 \%$ Espírito Santo & $\leq 1.0 \%$ Pernambuco & $\leq 1.0 \%$ Sergipe \\
\hline$\underline{1.0 \%}$ Goiás & $\leq 1.0 \%$ Piauí & $\leq 1.0 \%$ Tocantins \\
\hline 4. [If Brazil] Cit & & \\
\hline$\leq 1.0 \%$ Belém & $\leq 1.0 \%$ Goiânia & $\underline{7.4 \%}$ Rio de Janeiro \\
\hline$\underline{1.7 \%}$ Belo Horizonte & $\underline{46.1 \%}$ Manaus & $\leq 1.0 \%$ Salvador \\
\hline$\underline{3.0 \%}$ Brasília & $\underline{1.3 \%}$ Novo Airão & $\leq 1.0 \%$ Santarém \\
\hline$\leq 1.0 \%$ Cuiabá & $\leq 1.0 \%$ Ponta Grossa & $\underline{15.2 \%}$ São Paulo \\
\hline$\underline{1.6 \%}$ Curitiba & $1.6 \%$ Porto Alegre & $\underline{17.9 \%}$ Other (Please specify): \\
\hline$\underline{1.1 \%}$ Fortaleza & $\leq 1.0 \%$ Recife & Open \\
\hline
\end{tabular}

5. What is your age? _Mean $=39.80$

6. What is your gender? $45.0 \%$ Male _55.0\%_Female

7. What is your education level? Please select one option:

2.2\%_Elementary _20.8\%_High School _ $12.4 \%$ _Some College $\quad \underline{35.1 \%}$

College Graduate $\quad \underline{29.5 \%}$ Post Graduate

8. How far in advance did you plan your trip to the Forest/National Park? Please select one option:

$-14.0 \%$ today $\quad 20.2 \%$ 2-3 days _ $\quad 11.3 \%$ 4-7 days $\quad 5.3 \%$ 8-14 days

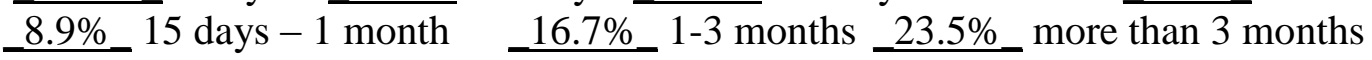

9. Is this your first visit to this National Forest/National Park? _83.7\%_Yes _ $16.3 \%$ No

10. [If no] Year in which you made your first visit to this Forest/National Park (Ex: 2004):

$\underline{\text { Mean }=2008.60}$

11. [If no] In a typical year, how many days do you come to this National Forest/National Park?

$\underline{\text { Mean }=3.15}$

12. Is your trip today... $\underline{63.2 \%}$ an overnight visit to this area $\underline{36.8 \%}$ a day trip

13. [If overnight] How long is your visit? $\underline{\text { Mean }=4.62 \text { days }}$ 
14. [If a day trip] How long is your visit? Mean $=4.35$ hours

15. What transportation mode(s) did you use to arrive at this site today? _4.3\%_Taxi_58.7\%_Private car _7.2\%_Rental car_ _.3\% Motorcycle _3.9\%_ Public Bus 3.6\%_Private Bus_<1.0\% Bicycle --- Train $3.0 \%$ On foot _ $13.8 \%$ Boat $\_3.4 \%$ Speedboat _1.7\%_Airplane (only if arriving at this specific site by airplane) $\leq 1.0$ Other [Please specify]_open_

16. How many adults are in your group today? _Mean $=4.08$

17. How many children under 16 years of age are in your group today? _Mean=2.10

18. Which of the following best describes the composition of your group? Please select an option:

5.1\% Alone $\underline{25.6 \%}$ Couple $\underline{37.0 \%}$ Family $\_$15.0\% Friends _ $9.5 \%$ Family and Friends

$3.6 \%$ Commercial Group (group of people who paid a fee to participate in this trip)

$\underline{2.8 \%}$ Organized Group (club or other organization)

$\leq 1.0 \%$ Education

$\leq 1.0 \%$ Other [Please specify]_open_

19. What activities have you participated in during this visit?

_31.2\%_Hiking _50.6\%_Swimming _7.7\%_Barbeque _38.1\% _ Lunch/Picnic

7.9\% Viewing Waterfalls $49.3 \%$ Boating / Canoeing $\underline{76.7 \%}$ Viewing Wildlife

$\underline{2.5 \%}$ Snorkeling / Diving $\leq 1.0 \%$ Kite Surfing ---Exploring dunes with a motor

vehicle $\leq 1.0 \%$ Rafting $\leq 1.0 \%$ Gliding $2.6 \%$ Canyoneering --- Mountain Climbing / Climbing 2.0\% Visiting the caves --- Use of riding animals 3.8\% Camping $18.8 \%$ Buying

Crafts $\underline{19.6 \%}$ Community Area $11.5 \%$ Get to know a famous tourist attraction 3.2\% Other [Please specify]_open

20. Which one of those is your primary activity for this recreation visit? Please select one option:

12.1\%_Hiking 9.1\%_Swimming_<1.0\%_Barbeque _1.8\% Lunch/Picnic 3.0\% Viewing Waterfalls $\underline{7.8 \%}$ Boating / Canoeing $\underline{41.4 \%}$ Viewing Wildlife $\leq 1.0 \%$ Snorkeling /

Diving $\leq 1.0 \%$ Kite Surfing --- Exploring dunes with a motor vehicle --- Rafting -.- Gliding --- Canyoneering --- Mountain Climbing / Climbing --- Visiting the caves ---Use of riding animals $\leq 1.0 \%$ Camping $\leq 1.0 \%$ Buying Crafts $\underline{1.3 \%}$ Community Area $\underline{10.7 \%}$ Get to know a famous tourist attraction $9.8 \%$ Other [Please specify]_open

21. Of the following, what was the main reason for your visit? Please select an option:

9.9\% I came because I like the place itself

$5.0 \%$ I came because it's a good place to do the outdoor activities that I like

$\underline{10.6 \%}$ I came because I want to spend more time with my friends/family

$\leq 1.0 \%$ I came because it is close to home

$\underline{48.2 \%}$ I came because I enjoy nature

25.6\% I came because it's a good place to experience the culture of this area

22. Overall, how would you rate your visit to this area today? Mean $=\underline{4.57}$ 


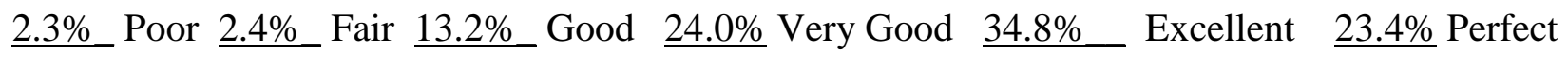

23. In general, how would you rate the quality of each item on a scale from 1 to 5 , with 1 meaning poor and 5 meaning excellent?

\begin{tabular}{|l|c|c|c|c|c|c|c|}
\hline & Poor & Fair & Good & $\begin{array}{c}\text { Very } \\
\text { Good }\end{array}$ & Excellent & $\begin{array}{c}\text { Not } \\
\text { Applicable }\end{array}$ & Mean \\
\hline Cleanliness of area & $1.1 \%$ & $7.0 \%$ & $36.3 \%$ & $25.5 \%$ & $29.2 \%$ & $<1.0 \%$ & 3.76 \\
\hline Safety and Security & $<1.0 \%$ & $3.8 \%$ & $33.0 \%$ & $26.7 \%$ & $33.9 \%$ & $2.0 \%$ & 3.91 \\
\hline Trail Condition & $<1.0 \%$ & $1.7 \%$ & $13.9 \%$ & $17.3 \%$ & $20.9 \%$ & $46.1 \%$ & 4.06 \\
\hline Facilities & $1.3 \%$ & $7.9 \%$ & $31.4 \%$ & $21.8 \%$ & $24.5 \%$ & $13.1 \%$ & 4.00 \\
\hline Access Roads & $13.0 \%$ & $14.7 \%$ & $29.7 \%$ & $21.0 \%$ & $17.9 \%$ & $3.7 \%$ & 3.17 \\
\hline $\begin{array}{l}\text { Environmental } \\
\begin{array}{l}\text { Interpretation } \\
\text { (panels, guides, } \\
\text { brochures, etc.) }\end{array}\end{array}$ & $8.3 \%$ & $15.3 \%$ & $25.2 \%$ & $21.3 \%$ & $23.2 \%$ & $6.8 \%$ & 3.38 \\
\hline
\end{tabular}

24. How did the number of people you saw today affect the overall enjoyment of your trip?

\begin{tabular}{ccccccccc}
$2.6 \%$ & $<1.0 \%$ & $1.2 \%$ & $<1.0 \%$ & $25.8 \%$ & $5.4 \%$ & $12.2 \%$ & $17.2 \%$ & $34.5 \%$ \\
-4 & -3 & -2 & -1 & 0 & 1 & 2 & 3 & 4 \\
\hline
\end{tabular}

Reduced my enjoyment

No Effect

Enhanced my enjoyment 